\title{
A perception theory in mind-body medicine: guided imagery and mindful meditation as cross-modal adaptation
}

\author{
Felice L. Bedford
}

Published online: 8 November 2011

(C) Psychonomic Society, Inc. 2011

\begin{abstract}
A new theory of mind-body interaction in healing is proposed based on considerations from the field of perception. It is suggested that the combined effect of visual imagery and mindful meditation on physical healing is simply another example of cross-modal adaptation in perception, much like adaptation to prism-displaced vision. It is argued that psychological interventions produce a conflict between the perceptual modalities of the immune system and vision (or touch), which leads to change in the immune system in order to realign the modalities. It is argued that mind-body interactions do not exist because of higher-order cognitive thoughts or beliefs influencing the body, but instead result from ordinary interactions between lower-level perceptual modalities that function to detect when sensory systems have made an error. The theory helps explain why certain illnesses may be more amenable to mind-body interaction, such as autoimmune conditions in which a sensory system (the immune system) has made an error. It also renders sensible erroneous changes, such as those brought about by "faith healers," as conflicts between modalities that are resolved in favor of the wrong modality. The present view provides one of very few psychological theories of how guided imagery and mindfulness meditation bring about positive physical change. Also discussed are issues of self versus non-self, pain, cancer, body schema, attention, consciousness, and, importantly, developing the concept that the immune system is a rightful perceptual modality. Recognizing mind-body healing as perceptual cross-modal adaptation implies that a century of
\end{abstract}

F. L. Bedford $(\triangle)$

University of Arizona,

P.O. Box 210068, Tucson, AZ 85721, USA

e-mail: bedford@u.arizona.edu

URL: www.email.arizona.edu $\sim$ bedford cross-modal perception research is applicable to the immune system.

Keywords Psychoneuroimmunology · Guided imagery . Health · Cognition · Mindfulness meditation · Cross-modal perception $\cdot$ Mind-body $\cdot$ Perception $\cdot$ Prism adaptation . Visual imagery

\section{Introduction}

In this article, a novel perception-based theory of mind-body interactions is suggested. The idea that the mind may influence the body has long been intriguing to psychology, philosophy, religion, medicine, neurobiology, and popular culture. The placebo effect has been used by physicians for centuries (A. K. Shapiro, 1959), and faith healers are as old as organized religion itself (Porterfield, 2005). They both reflect the longheld idea that mere thought may bring about positive physical change. In psychology, contemporaries of Pavlov demonstrated more than 80 years ago that the immune system can be conditioned (see Hull, 1934; Spector, 2011). Pairing a neutral stimulus, such as a scratch on the skin, repeatedly with a substance that causes an increase in white blood cells, such as the injection of bacteria, led to the neutral stimulus by itself eliciting a large increase in white blood cells. Thus, the same Pavlovian learning process by which a tone can elicit fear if paired with shock or salivary anticipation if it precedes food can also produce an immune system response inside the body. The finding was an early lab demonstration that a psychological process, albeit not a higher-order cognitive one, can affect a physical process.

However, it is only recently that mainstream science and medicine have taken an interest in the influences of mind on health. Mention that the immune system could be 
conditioned appeared in early texts (Hilgard \& Marquis, 1940) but was omitted in later editions. It was seemingly forgotten entirely in some literatures when it was reportedly first "discovered" decades later (Ader \& Cohen, 1975), but with its import now recognized. In addition, accumulating findings on the relation between psychological states and disease were being documented in animals and humans. Stress in rats led to more infectious disease (Rasmussen, Marsh, \& Brill, 1957). Stress caused by death of a spouse caused decline in immune functioning, later identified as natural killer cells, later shown to protect against viral disease and tumors (see Irwin, 2008). Depression predicted mortality in cancer patients (who also smoked; Linkins \& Comstock, 1990). Social connectedness was found to be linked to overall health, and possibly to longevity (House, Landis, \& Umberson, 1988). Another important contribution to taking mind-body interactions seriously was discoveries that the brain and the immune system are able to communicate. Brain neurotransmitters and receptors were found to also exist in the immune system, while immune system chemicals, such as interferon and interleukin-1, were found to affect the brain (see, e.g., Blalock, 1989; Irwin, 2008; Pert, Dreher, \& Ruff, 1998). The discovery of such shared messengers between these two systems provided evidence that physical mechanisms that can instantiate mind-body interactions do indeed exist. Finally, in everyday culture, the well-known Harvard-trained physician Andrew Weil helped legitimize and popularize the pursuit of alternative medicine (Weil, 1995), including the role of psychological interventions. Consequently, the pursuit of mind-body medicine is no longer on the fringes of acceptable inquiry. An interdisciplinary field has emerged to study the relation between the mind, the nervous system, and the immune system (see Vedhara \& Irwin, 2005), termed "psychoneuroimmunology" by the rediscovers of immune system conditioning. It is now a reputable branch of study that has been growing rapidly.

While it might be convincing that understanding mindbody medicine is a legitimate goal of scientific inquiry, one may ask what any self-respecting perception researcher is doing being interested in such processes. I suggest that perception research should play a central role in this endeavor. The goal of the present article is to defend the claim that perceptual processes are central to mind-body interactions by introducing a new perception-based psychological theory. The theory can help explain the arguably mysterious effects of some frequently used psychological interventions on the body that are intended to bring about positive physical changes to health. Note that this article is not intended to be a review of the literature on the effectiveness of psychological interventions on health. The aim is instead to show how such effects can be viewed from a novel perspective.
The article begins with a discussion of why perception in general should be involved in mind-body interactions (sec. 2). The specific perception theory is then presented, including the essence of the theory (sec. 3), then how it explains seeming failures in mind-body interactions (sec. 4), and how it explains why such interactions occur in the first place (sec. 5). The article continues with discussion of three assumptions of the theory, of detailed examination of the immune system is a sense modality (sec. 6), that visual imagery can substitute for vision in adaptation (sec. 7), and that mindfulness meditation plays a hidden role (sec. 8). Next are two brief comparisons of the theory to prevailing views, first the view on pain (sec. 9) and then one addressing more general existing approaches in mind-body medicine (sec. 10). Finally, the article concludes with a few new avenues that the theory suggests (sec. 11).

\section{Introducing the relevance of perception}

Two well-known psychological manipulations for bringing about positive change are guided imagery and mindfulness meditation. They are often used together in experiments and treatment (Elomaa, Williams, \& Kalso, 2009; Fernros, Furhoff, \& Wändell, 2008; Wells, 2010), and sometimes the line between different alternative interventions can get blurred. In guided imagery — or "visualization," as it is also known - the mind is directed to intentionally invoke images in order to bring about positive change. The imagination is used to conjure places or objects or events that are not externally present, with the aim of influencing psychological and physiological states (Achterberg, 1985; Post-White, 2002; Richardson, 1994). It is a commonly used intervention, and health benefits have been reported. For example, the frequency and intensity of chronic abdominal pain in children was reduced following imagery training (Ball, Shapiro, Monheim, \& Weydert, 2003). In a recent study, guided imagery in women with breast cancer led to altered immune system functioning, including increased natural killer cells and lymphokine activated killer cells (Eremin et al., 2009). Although guided imagery scripts vary greatly (Bresler \& Rossman, 2004; La Roche, Batista, \& D’Angelo, 2011; Roffe, Schmidt, \& Ernst, 2005; Utay \& Miller, 2006) and can incorporate components such as relaxation, increased focus of attention, and music, the common core of the treatment remains imagery, usually visual.

To introduce the relevance of perception, consider simply that perceptual processes are clearly involved in visual images that are formed in the absence of external stimuli. Mental imagery has been the subject of extensive research in the perception field, beginning as a rebellion against behaviorist traditions in psychology that denied the existence of relevant mental representations. Finke and 
Shepard (1986) reviewed the different areas in which there appears to be functional equivalence between visual imagery and real vision. That is, they showed that images created in the mind can substitute for the visual perception of an object in the environment. One well-known example they reviewed concerns the mental rotation of objects (Shepard \& Judd, 1976). The reaction time to indicate whether two polygons are the same or are mirror images of each another increases nearly linearly with the degree of rotation between the two figures, suggesting that participants form an image of a target rotating into alignment with the other. Evidence for mental rotation comes from the presentation of figures of intermediate orientation; following instructions to rotate a polygon clockwise, a polygon at an intermediate rotated angle is presented that either does or does not coincide with where the target should be if the participants were mentally rotating. Shepard and Judd found that coinciding stimuli could be judged quickly for a "same" versus a "mirror image" response, independent of the absolute orientations of the coinciding stimuli, whereas reaction times to noncoinciding stimuli were slower and varied nearly linearly as a function of the degree of rotation between the intermediate target and the intermediate mental image. Thus, visual imagery of an object rotating goes through intermediate angles to get to the intended orientation, just like an actual rotating object that would be seen with real vision.

Another notable example of how visual processing is involved in visual imagery concerns the inducement of an orientation-contingent color illusion-the McCollough effect-except using imagined rather than real color (Finke \& Schmidt, 1977). In the McCollough effect, the presentation of green vertical lines (i.e., square wave gratings with alternating green and black vertical bars) alternating with magenta horizontal lines for several minutes leads to a long-lasting aftereffect in which vertical white bars look pink and horizontal bars look greenish. In the imagery version, instead of real color, participants form a visual image of color on the bars during the few minutes of exposure. This also leads to color aftereffects that are contingent on the orientation of the test stimulus. The effect is notable because participants do not know what to expect, and it is difficult to think of a mechanism alternative to imagery that causes participants to actually see color on a black-and-white test display. This result is also notable because it is an example of using imagery to get perceptual change, which is particularly relevant in the present theory, as will be seen.

Empirical research on visual imagery has therefore revealed it to be capable of complex achievements, as if the target of imagery is actually there, rather than just some vague notion of an amorphous visual sensation. Neuropsychological findings are consistent with the behavioral data that imagery can be functionally equivalent to vision (Farah, 1988). Patients who lose a specific visual ability, such as color or spatial localization, also have a selective deficit in imagery for that property. The data suggest that visual imagery shares at least some brain hardware with real vision (but see Behrmann, Moscovitch, \& Winocur, 1994, discussed patients who lose one ability but not the other). In sum, perceptual processes are involved in visual imagery. The examples also illustrate the complex experimentation that has been conducted on imagery abilities.

Yet, interestingly, despite the rich history of perceptionbased research on imagery, guided imagery as a therapy does not refer to perception research. Instead, it has origins that include very different areas in psychology, such as Freudian psychotherapy and systematic desensitization treatment for phobias (Achterberg \& Lawlis, 1987; Simonton, Simonton-Matthews, \& Creighton, 1992) Consequently, interests for mind-body research and treatment have reflected those origins. For instance, one issue of concern is that an instructed image will have unique effects on each individual because of different personal, social, and emotional histories (Wolpe, 1973). This is different from the kinds of questions that perception researchers would bring to bear.

Turning to the second common mind-body intervention, mindfulness meditation is an ancient spiritual practice in the Eastern part of the world and a component of Buddhism. Jon Kabat-Zinn's "mindfulness-based stress reduction" (Kabat-Zinn, 2005) instruction has brought mindfulness meditation to Western medicine. It has been given to thousands of patients with conditions including heart disease, cancer, and chronic pain. It is the subject of well over a hundred published scientific articles and appears to have positive physical benefits. For instance, patients with the HIV virus had stronger natural killer cell counts after a month of training, as compared to controls without the intervention, whose counts went down (Creswell, Myers, Cole, \& Irwin, 2009). Is perception also applicable to mindfulness?

An exercise central to Kabat-Zinn's training program is known as "body scanning," in which the subject focuses attention on successive parts of the body, beginning with the left foot and ending with the head, in order to become mindful of the precise feelings and sensations (Kabat-Zinn, 2005). From the perspective of perception, body scanning appears to involve the body schema and proprioception. Body schema is a concept that has been known in the field of perception for a hundred years (Head \& Holmes, 19111912). It involves having a mental representation of the shapes and positions of the body. Knowing where movable parts of the body are at all times is essential for accurate reaching and avoiding obstacles. It is even important for visual perception, because it allows the discounting of 
motions of the self from the retinal image, to produce for accurate interpretation of the retinal image. Proprioception is a related concept that facilitates construction of the body schema. It is considered part of the touch sense modality and involves the felt position sense of body parts. If you close your eyes, you can feel your arm and where it is, even though you are not looking at it. Like visual imagery, body schema and proprioception have been the participants of research in perception. One example relevant to perceptual change is that the boundaries of body schema are not fixed (see, e.g., Cardinali et al., 2009; Merzenich et al., 1983) and can even incorporate inanimate objects. After practicing actively using a tool, it becomes part of the body schema. Evidence comes both from behavioral and brain data. Behaviorally, crossing body parts generally can lead to errors in body schema, and crossing the arms at the forearms specifically leads to a disruption or illusion of body schema concerning which hand is touched. Following practice with two long tools held in the hands for reaching, crossing the tools leads to the same illusion concerning which hand is touched (via vibration through the ends of the tools), even though the arms remain uncrossed (Yamamoto \& Kitazawa, 2001). In the brain, recording from cells from the inferotemporal cortex in the macaque finds neurons that will respond to either tactile or visual stimuli in the same region; these neurons show plasticity with tool use, such that the visual receptive field of a neuron that previously responded to the region of the hand now expands to include the region encompassing the hand plus tool (Maravita \& Iriki, 2004). As with guided imagery, mindfulness (mindful) meditation has its own traditions and does not make use of the often interesting perception-based research on body schema.

Other exercises in mindful meditation include paying close attention to breathing, to one's own thoughts, or to sounds: "just hearing what is here to be heard, moment by moment. . . . Just hearing them as them as pure sound" (Kabat-Zinn, p. 73). Mindful meditation has been summarized as "bringing one's attention to the internal and external experiences occurring in the present moment" (Baer, 2003), whether the focus of the meditation is the body (body scan), sounds (sound meditation), sights, or one's own thoughts. From a perception perspective, the practice involves greater than usual attention to exact perceptual stimulation over space and time that comes through any sense modality. In other words, the procedures of mindful meditation start to suggest starring roles for perception and attention.

Finally, consider introspectionism from early 20th-century psychology, then a legitimate scientific method for studying sensation and perception (Wundt, 1912/2009). In that methodology, observers would focus on and describe every minute sensation. Such greater than usual attention required extensive training on sustaining focus and introspecting on experiences, not unlike mindful meditation. It would be interesting to know whether the training led to any unintended consequences similar to meditation, such as increased relaxation. These details are not typically reported.

In general, the study of mind-body interactions would benefit from perception's cumulative body of knowledge and its paradigms for investigating problems. This would be especially helpful for elucidating underlying psychological mechanisms.

\section{Mind-body interaction is cross-modal adaptation}

The perception approach put forth here is that observed physical change to psychological interventions is actually just another example of perceptual adaptation, much like spatial adaptation to prism-displaced vision. Prism adaptation is the paradigmatic example of cross-modal adaptation (Chapman et al., 2010; Held, 1965; Helmholtz, 1866/2005; Rossetti et al., 2004; Welch, 1978). An observer looks at her own hand through a wedge prism with the thin end to the left. She feels the hand to be in one spatial location, but sees it in another a few inches to the left because of the prism. The perceptual system has the constraint that one object cannot be in more than one place at one time, including one's own hand (Bedford, 2004). Consequently, if it is concluded that the visual and proprioceptive input refer to the same hand then discrepancy between the seen and felt positions of the hand indicates that there is something wrong with our own perceptual machinery, and adaptation is the process by which this inferred internal error is fixed (Bedford, 1993a, 1993b, 1995, 1999, 2001): Either the felt position of the hand will shift to the left or the perceived visual location nudged to the right, so as to remove the discrepancy (Harris, 1965; Redding \& Wallace, 1990; Welch, 1978; Welch \& Warren, 1986).

Edwin Blalock, a neuroimmunologist, has argued that the immune system is a sense organ (Blalock, 1984; Blalock \& Smith, 2007): "A sixth sense, if you will, that completes our ability to be cognizant not only of the universe of things we can see, hear, taste, touch and smell but also the other universe of things we cannot. These would include bacteria, viruses, antigens, tumor cells and other agents that are too small to see or touch, make no noise, have no taste or odour" (Blalock, 2005, pp. 130-131). If the immune system is a sixth sensory modality then I suggest that a visual image of one's self fully healed along with an immune system that has detected that something is wrong reflect a conflict between modalities, much like the conflict between vision and proprioception in prism adaptation. The conflict between the vision and immune modalities implies that one or the other must change to remove the error and bring the modalities back in line. If the immune system is the modality 
that changes, we say that a mind-body connection has occurred.

Figure 1 illustrates adaptation, both for a visionproprioception conflict in prism displacement and for the visual imagery-immune system conflict suggested for mind-body healing. Before adaptation, there is a conflict between modalities, and during the process of adaptation at least one of the modalities must shift. When the process of adaptation is complete, successful adaptation realigns the two modalities such that they are once again in agreement.

Central to adaptation is establishing a conflict between the two modalities. Visual imagery can be functionally equivalent to actual vision, rather than providing only a vague sensation, as discussed in the previous section. Consequently, visual imagery appears capable of providing usable visual information for comparison to other modalities (see also sec. 7). Experiments that use guided imagery for healing often include instruction for images that are or will lead to being fully normal, healed, and restored and that give a sense of well being (Baird, Murawski, \& Wu, 2010; Ball et al., 2003; Carrico, Peters, \& Diokno, 2008; Eremin et al., 2009; Fernros et al., 2008; Menzies \& Kim, 2008; Menzies, Taylor, \& Bourguignon, 2006; Nunes et al., 2007; Walker et al., 1999; Wells, 2010). The positive content of these images provides the conflict with the immune system information, which in contrast indicates something abnormal, such as a cancer cell.

If mind-body interaction reflects cross-modal adaptation then the stronger the conflict between the modalities, the greater the change will be. In prism adaptation, vibrating the arm that is seen through the prism appears to strengthen the proprioceptive signal of the arm ("increase in salience"), which leads to a greater change in the visual modality (Kravitz \& Wallach, 1966) Conversely, weakened conflict leads to less adaptation; having one's arm moved passively while watching it through a prism leads to less adaptation overall than does actively moving the arm oneself (Held, 1965). ${ }^{1}$ Information obtained from self-generated active movement is believed to provide stronger information for calibrating modalities than does passive movement (Held, 1965; Held $\&$ Hein, 1963). For mind-body change, it is expected that stronger visual imagery should be capable of producing greater change in the immune system, much like a stronger proprioceptive arm signal produces greater change in vision. Consistent with this account is a finding that participants who report the most vivid visual images from the very first training session also show the greatest

\footnotetext{
${ }^{1}$ There are two issues here. One is the relative strength of one modality leading to greater changes in the other modality. The second is the overall strength of a conflict leading to greater total adaptation in both modalities combined. Both factors are expected to influence the amount of change in the immune system in mind-body adaptation.
}

healing (Bedford, 2011; Bedford \& Peterson, 2010; Spanos, Stenstrom, \& Johnston, 1988). Visual imagery ability varies widely in the population, and in the present view, the greater the imagery ability, the greater the crossmodal conflict and the greater the change. Self-report of imagery vividness is found to correlate with usable imagery. As noted in the previous section, the aftereffect of the McCollough effect, in which observers see color on white bars contingent on the bars' orientations, can be generated with imagined rather than actual colors. Finke (Finke \& Schmidt, 1977) also found that the participants who reported the strongest imagery had a stronger McCollough effect. Thus, higher self-report of imagery likely reflects a stronger visual image, which should lead to a greater cross-modal conflict and a greater change in the immune system.

Interestingly, participants have found it harder to "visualize your condition healed" than to be able to form "vivid visual images" during the technique (Bedford \& Peterson, 2010, p. 1). It may be especially difficult to visualize a counterfactual situation. Yet, in the present theory, this is the very ingredient needed for adaptation/ healing; in the event of resistance, it may be the immune system that is changing vision, rather than the other way around. This issue will be addressed in Faith healers and counteradaptation section.

Also in the present theory, some physical conditions should be especially amenable to positive change through psychological intervention. A patient with dermatomyositis was cured following the better part of a year with visual imagery and (transcendental) meditation (Collins \& Dunn, 2005). Dermatomyositis is an autoimmune reaction to muscle tissue and skin; the inflammation and degeneration lead to debilitating muscle weakness and skin rash, and it is a potentially fatal disease. The researchers concluded that visual imagery was effective because it was mediated by the humoral immune system. The immune system is divided into innate immunity and adaptive immunity (Janeway \& Travers, 1999). Innate immunity is fixed and does not change with the environment, whereas adaptive immunity instead can generate receptors for foreign invaders (antigens) that it has encountered previously. Adaptive immunity is further divided into humeral immunity and cellular immunity, each with a different specialty. Humeral immunity (B cells) is especially good at detecting foreign objects; it also recognizes foreign objects without any processing of the object and produces antibodies and complement to destroy them. Cellular immunity (T cells) can detect cells of its host body that have been tainted, can detect peptides, and directly destroys invaders instead of producing antibodies or complement. Collins and Dunn's conclusion was based on their review of the available 
Fig. 1 Cross-modal adaptation. The illustration shows adaptation to conflicts between (left) vision and proprioception concerning the location of an object and (right) visual imagery and the immune system concerning the health of a cell. The top row shows the situation "before adaptation," when there is a conflict between the information obtained by two modalities. The middle row depicts what happens during adaptation when one or more modalities shifts in the direction of the other. Shown is the nonvisual modality beginning to change toward vision in each case. The bottom row refers to the state after adaptation, when recalibration is complete and the modalities once again provide identical information on the shared parameter. It is argued here that mind-body healing is a reflection of adaptation to conflict between sensory modalities, just as in spatial adaptation

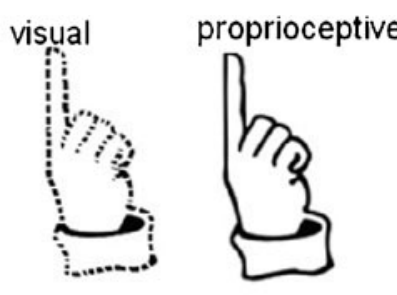

visual immune
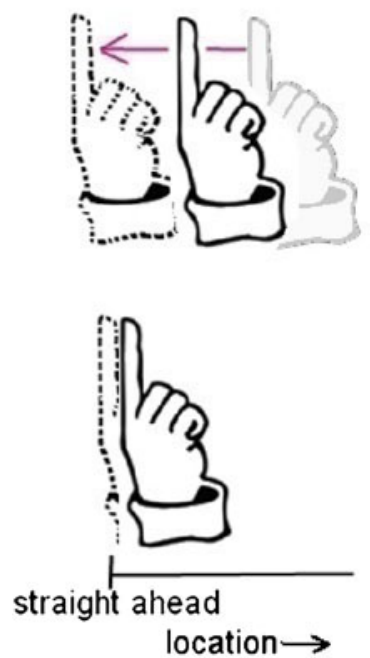

\section{before adaptation}

during adaptation
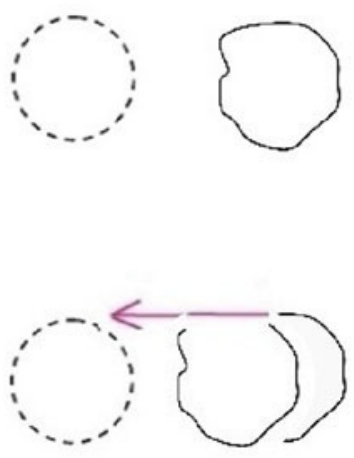

adaptation

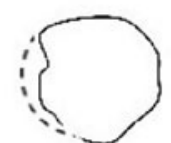

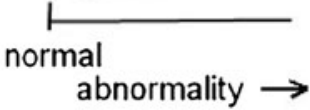

literature, which seemed to suggest that imagery was shown to be effective in cases in which humoral immunity occurred. An explanation for why the humeral immune system should be more susceptible to imagery than the cellular immune system was not offered.

The present perceptual account has a different type of explanation altogether. In the view that mind-body healing is cross-modal adaptation, autoimmune disorders are perfectly suited to cross-modal adaptation. In autoimmune reactions, the body launches an attack on its own cells, mistaking them for foreign antigens (Beers, 2006). That is, the immune system has made an error! It is therefore an ideal candidate for correction through adaptation. Recall that in cross-modal adaptation, an error is inferred because of conflicting information provided by the sensory systems. The very function of adaptation is to correct internal errors in sensory systems (Bedford, 1993a, 1993b, 1995, 1999), whether they be in vision, proprioception - or the immune system. Issues related to the function of adaptation will be addressed further in Why mind-body interactions occur section.

Other areas of especially successful interventions on physical disorders may also be explicable in the present view. Folk wisdom singles out skin conditions as especially changeable. In self-help books, it is noted that magical thinking and the power of suggestion have been used for years by pediatricians to cure warts in children (Editors of Prevention Magazine Health Books, 2003). The experi- mental literature appears to support this folk view, with consistently successful psychological interventions for skin disorders. In a study on psoriasis (Kabat-Zinn et al., 1998), patients in an experimental group were given visual imagery and mindful meditation with focus on breathing and the body scan exercise, in addition to receiving standard ultraviolet light therapy. Patients with psoriasis have scaly skin patches caused by an increased growth rate of skin cells. Imagery in the experimental group consisted of having participants visualize the ultraviolet light causing the cells to slow down their growth by jamming the machinery that allows skin cells to divide. After 40 sessions over 12 weeks, 10 of 13 participants in the experimental group had completely clear skin, as judged by dermatologists blind to group assignment, as compared to 2 people out of 10 in an ultraviolet-only control group. A study in a different lab on warts used combinations of visual imagery, hypnosis, relaxation, and positive suggestions (Spanos, Williams, \& Gwynn, 1990). Wart regression imagery included instructions to "vividly imagine their warts shrinking and dissolving away" (p. 111), which participants practiced for 2 min per day. Following 6 weeks of practice (approximately 45 sessions), the average number of warts was half the number before intervention (from 2.4 to 1.3 ), as compared to no wart loss in groups receiving either a cream containing salicylic acid or a cream with neutral nonactive ingredients. Out of 10 participants in each group, 6 who 
received imagery instructions lost at least one wart, whereas none of the participants lost warts in the salicylic acid group, 1 lost warts in the neutral cream group, and 3 lost warts in a fourth group who were told that they would receive treatment in 6 weeks. According to the present adaptation account, responsiveness in these skin conditions may in part be due to errors made by the immune system, as in the argument for dermatomyositis. Warts result from the immune system being tricked by the papilloma virus into providing "free room and board" (Editors of Prevention Magazine Health Books, 2003, p. 802 ), and psoriasis is believed to involve an autoimmune component (Lowes, 2004).

Two additional factors from the present perspective may contribute to successful intervention in skin conditions that are themselves intriguing. First, we get to see our own skin frequently in the course of everyday activities. This should make visual images of skin in the mind's eye relatively easy, which would increase the strength of the conflict and lead to greater change. Thus, in the present view, skin disorders should be among the easiest to improve. Second, the skin itself involves a sensory modality - touch — in a way that internal organs do not. Visualizing the skin healed may introduce interactions between three modalities, vision, touch, and the immune system. Investigation of the interaction of three modalities is much less frequent than between two modalities in the perceptual adaptation literature, and such interactions can lead to unexpected results (Bedford, 2007a). Three-modality interactions and the effects of being able to see our own skin warrant further investigation.

While this section has introduced the theory and discussed how mind-body successes are explained within the theory, it is also illuminating to consider disappointing results of mind-body interventions.

\section{Faith healers and counteradaptation}

Excitement and wailing can be heard in the background. There is a laying on of hands, a question about faith, a declaration of healing - and soon Johnny is no longer in excruciating pain. "It's a miracle!" someone shouts. And it is. Until Johnny is found dead 2 days later from a ruptured appendix. This familiar class of examples has led skeptics to the conclusion that mind-body interaction, at best, only makes people think they are healed but does not affect the disease process itself. Such seeming failures are readily explicable in the context of a perceptual interpretation of mind-body effects. Other, more recognized instances of perceptual adaptation also have the equivalent of faith healing. In prism adaptation, discussed above, the disagreement between vision and proprioception is often resolved by shifting the proprioceptive, or felt location, of the arm to agree with vision (Harris, 1965; Welch \& Warren, 1986), even though it is the visual location of the arm that is incorrect. Hans Wallach (Wallach \& Frey, 1972) used the label counteradaptation (italics added) to describe the effect. He used the label to draw attention to the fact that such a change to the wrong modality is anything but adaptive (see also Bedford, 2007a). If not in the confines of a protected laboratory, mistaking an error in visual location for an error in arm location would be as harmful to survival as mistaking the hot appendix for a minor ache. The faith healer did cure the pain, but curing the pain in this instance was a bad idea. The pain was right, the imagery wrong.

Disappointing results of imagery on physical aspects of cancer in some studies may similarly result from a resolution between the conflicting modalities that does not suit the host. For example, women receiving relaxation visualization therapy (RVT) while undergoing radiation treatment for breast cancer did not show biological improvement, as measured by $\mathrm{T}$ cells and cortisol levels, though they did show reductions in depression, stress, and anxiety (Nunes et al., 2007). A conflict between vision (normalcy, wellbeing) and the immune system (something wrong, under attack) can lead to adaptation in which vision wins and the immune system no longer detects a threat. Getting the immune system to stop attacking is what is needed in autoimmune illnesses, but would be exactly the wrong resolution in cancer. What one wants instead is to turn on the immune system in the event that the immune system had failed to detect the cancer cells. This would require conflicting visual information that something is very wrong, not that the person is healed or peaceful. RVT included visualizing the breast fully healed and imagining tumor cells under attack by the immune system. "Fully healed" imagery would provide the wrong conflict for cancer, visualizing tumor cells the right conflict, and visualizing an attack likely the wrong conflict. This type of mixture is fairly common in imagery training for cancer (Moyé, Richardson, Post-White, \& Justice, 1995). Guided imagery treatment in cancer often includes images that emphasize healing, positivity, and inner strength, along with seeing the tumor cells in the mind's eye (Eremin et al., 2009; Kwekkeboom, Hau, Wanta, \& Bumpus, 2008; Nunes et al., 2007; Walker et al., 1999). It may be counterintuitive for practitioners to use imagery that emphasizes illness, which may account for some failures of imagery's effectiveness on biological markers in cancer. But emphasizing illness through another sense modality is exactly what it is needed. Note also that cancer treatments currently have fewer side effects than they have had previously. It would be interesting to compare equivalent chemotherapeutic agents under conditions in which there are visual markers of illness, such as hair loss, and when there are not. 
The present theory predicts that the former conditions should be more effective, despite our natural repulsion to such treatments.

In general, the issues of (1) whether mind-body interactions work and (2) whether the outcome is adaptive are distinct. We turn now to the issue of the function of mind-body interactions in general.

\section{Why mind-body interactions occur}

This theory may also help explain why mind-body effects exist at all (Harrington, 1999; A. K. Shapiro \& Shapiro, 1997; Zajicek, 1995). Processes most important for survival and reproduction are not influenced by cognitive abilities of expectations, beliefs, wishes, and so on. For instance, body processes such as the amount of magnesium in the blood or the detoxification of chemicals by the liver occur automatically. They are both out of conscious awareness and are not influenced by conscious, higher-order mental processes. General-purpose higher-order abilities tend to be slow, subject to false beliefs, to be inconsistent, and to require attention, any of which could disrupt essential functioning. Such cognitive impenetrability is so important that it applies even to domains that involve mind and not just body. For instance, we are aware of when sexual attraction does or does not occur, unlike the state of our magnesium levels, but it is nonetheless automatic and determined by an evolutionarily defined high mate value; it is not changed by reasoning, deliberation, or any other cognitive appraisal (Ellis, 1992), much as we might wish that it were. Early vision is another example of cognitive impenetrability (Pylyshyn, 1999). Consider the Müller-Lyer visual illusion. Two line segments of identical length do not look identical because of the addition of a pair of shorter lines at each end-pointing either outward at a $45^{\circ}$ angle, which makes line segments look longer, or inward at a $45^{\circ}$ angle, which makes them look shorter. Importantly, even watching the illusion being drawn and observing for oneself that the two lines are identical before the additional segments are added does not detract from the illusion. The observer now emphatically believes that the two lines segments are the same length, but this belief cannot override the automatic perceptual output that they are different lengths. They still look different. Accurate vision is important for survival and, ordinarily, beliefs and other higher-order mental abilities would make vision less accurate and slower.

If even cognitive processes can be cognitively impenetrable, one would think that the immune system, at first glance more like the liver in the body than like visual perception in the mind, would also be shielded from higherorder mental abilities. Why should what we think influence the immune system, a process that is so important for survival? Andrew Weil, for one, did not have an answer (personal communication, University of Arizona colloquium). In the present account, the mind-body interactions do not reflect a higher-order cognitive influence on the body at all. This is why they can occur. The immune system is as cognitively impenetrable as the liver or the blood or sexual attraction or early vision. Instead, what appears to be a special higher-order cognitive influence of thought, feelings, beliefs, and desires on the immune system is actually just the everyday interaction of sensory modalities operating at the same preconscious, low level-namely, perceptual adaptation between the sense modalities of vision and the immune system.

Perceptual adaptation serves an important evolutionary function. Any biological system, including a sensory system, is subject to error. Adaptation corrects the error to restore peak performance. The role of conflict is critical in the process of detecting the errors. Otherwise, there would be a problem with knowing that a perceptual output resulted from an error rather than indicating something new about the world (Bedford, 1999). It is the latter that perceptual systems are supposed to do, while at the same time needing do so accurately. If you feel your arm to be straight ahead, it may be because the arm really is straight ahead. Alternatively, it could be a faulty proprioception output and your arm is located somewhere else. If the output of the visual modality indicates a different location, then proprioception, vision, or both can be inferred to have made an error. Conflicts and their implications occur between modalities other than vision and proprioception. Hearing a dog bark in one location but seeing the same dog in another location at the same time indicates faulty auditory or visual localization. (More precisely, the output of auditory localization processing conflicts with the output of visual localization processing, because the terms "hearing" and "seeing" imply conscious awareness, whereas typically the outputs of two conflicting modalities do not both reach conscious perception; see, e.g., Radeau \& Bertelson, 1976.) Modalities can also conflict about parameters other than location. Seeing that a cup is too tall for the kitchen shelf may occur because the cup is too tall for the shelf, or because vision erroneously conflicts with touch, which indicates it is really half that height. Likewise, detection of a faulty cell by the immune system could occur because it is a bad cell, which would require destruction, or the detection could be an error in the immune system output, which would require modifying the immune system, not destroying the cell. Information about that cell from another modality, such as vision/visual imagery, can disambiguate the situation, as it does for proprioception or audition. In general, interactions between systems that address the same parameter serve an important adaptive function of checking for errors in perception (Banks, 1988; Bedford, 1993b, 1999; Wallach, 1968) that will occur in all sense modalities, including vision, audition, touch/proprioception, and - as is argued here - the immune system. 


\section{The perceptual sixth sense of the immune system}

The cross-modal adaptation account of healing depends on neuroimmunologist Blalock's ingenious assertion that the immune system is a modality or sensory organ. How should psychology respond to this claim? What is needed is to determine whether the immune system meets a working definition and criteria of being a sensory modality. ${ }^{2}$ Discussion of these issues is the focus of this section. It is the longest section of the article, and readers not concerned with the development of this assumption of the theory can skip to the next section.

\section{Definition}

Sensory systems have been described as providing a "means for detecting a diverse set of external signals, often with incredible sensitivity and specificity" (Berg, 2002, p. 32.1), as specialized detectors for processing different kinds of energy (e.g., Pascual-Leone \& Hamilton, 2001), and as mechanisms that obtain and process information about the external world (e.g., Coren, Ward, \& Enns, 1999; Kuper, 2005). More specific definitions can be found within modalities. For instance: "Hearing allows an organism to use sound to detect, discriminate, and segregate objects in the surrounding world" (Yost, 2003, p. 121; see also de Cheveign'e, 2001). Note that definitions come from handbooks, textbooks, and summaries of perception for allied fields. Perception research itself tends not to discuss the fundamental assumptions implicit to the foundation of its own research. Nonetheless, commonalities in widely held definitions such as these can be identified. Above all, a sensory system is assumed to be detector, arguably for something external. Evaluating the immune system as a candidate for a sensory system thus requires, at minimum, consideration of how it measures up to this most general assumption.

\section{Criteria}

Ideally, there would further be a set of clearly explicated, current, agreed-upon set of necessary and sufficient conditions for formal membership into sensory modalityhood. Unfortunately, there are no such criteria. However,

\footnotetext{
${ }^{2}$ The vestibular system is also a candidate for a separate sense modality, though with a function more specialized (detecting orientation of the self) than other, more general perceptual modalities. This vestibular system will not be discussed here, but it is interesting to note that it may provide another example of cross-modal adaptation that has health implications. Adaptation occurs following conflict between the vestibular system and vision (Stoffregen, Draper, Compton, \& Kennedy, 2002), and motion sickness and vomiting can accompany the conflict.
}

candidates can be gleaned from two related questions that have been of more continuing concern to philosophy than psychology: How many sensory modalities are there, and how are modalities distinguished from one another (e.g., Fish, 2010; Keeley, 2002; Macpherson, 2010, 2011)? In addition, identifying properties that currently recognized sense modalities have in common may also elucidate properties that should be regarded as essential.

From these guiding principles, a list of five working criteria can be considered relevant to identifying sense modalities from a perception psychology perspective. (1) First, a stimulus is required. For instance, in vision, the stimulus is electromagnetic radiation, whereas in audition it is pressure waves. Related to the existence of a stimulus are (2) the existence of receptors specialized for the stimulus (in vision, this begins with rod and cone cells, and in hearing, with the basilar membrane hair cells) and (3) a dedicated organ (e.g., the eye and ear, respectively). Sensory systems can also be individuated on the basis of (4) what they represent, such as shape and location, and (5) most notable historically (see, e.g., the doctrine of specific nerve energies; Müller, 1835/2010), the type of sensation the modality gives rise to. In vision, observers have a particular experience unique to vision, often referred to as "seeing." This is in contrast to audition, where hearing sounds is a qualitatively different experience.

These criteria and the definition can be viewed as clustering into four aspects of a sensory system: namely, the input to the system (stimulus, specialized receptors, dedicated organ), its internal state (representations), what it outputs (type of sensation, i.e. conscious experience, but see below) and finally its function (from the definition: detection, external entities). In view of these considerations for being a sensory system, the candidate modality, the immune system, can now start to be assessed for how it measures up to the recognized modalities.

Input

Beginning with the input, the stimulus for the immune system can be identified as cells and molecules. Note that the stimulus is not "energy," which appears in some descriptions of the stimulus for sensory systems (e.g., Pascual-Leone \& Hamilton, 2001). Energy characterizes the electromagnetic radiation of vision and the propagating waves of air pressure disturbance for hearing. However, energy cannot be considered a necessary property of the stimulus for a sensory system, because the stimulus for olfaction is also molecules, in that case certain volatile ones capable of stimulating nasal epithelium (e.g., Stevenson, 2010). Similarly, the stimulus for taste is also chemical. The second aspect of input noted above concerns the existence of specialized receptors. The immune system passes this 
test as well. T cells and $\mathrm{B}$ cells detect the presence of foreign molecules previously encountered.

The final issue of input noted above concerns an organ of perception. The use of the term "organ" is ironic in this context. The word is borrowed from medically relevant bodily organs, like the liver or kidney, for use in sensory perception, and it is now being applied back to the medical domain. The issue of an organ of seeing, hearing, and so forth is arguably in part an issue of the distribution of the specialized receptors. The receptors for hearing all coalesce in a single region in a discrete organ of the ear. Likewise for vision, taste, and smell - within, respectively, the eyes, the tongue, and the nose. The immune system, on the other hand, has receptors distributed widely throughout the body. For instance, T cells and B cells circulate in lymphocytes in blood throughout the body. However, the immune system is similar to parts of the modality of touch, in which receptors for temperature, light touch, and heavy pressure are distributed throughout the body (e.g., Klatzky \& Lederman, 2003). In addition, human vision evolved from lightsensitive spots that were widely distributed (Dawkins, 1996), a sensory system that is found today in the earthworm. Thus, a particular distribution of receptors is not a criterion for a sensory system. Nor is the number of receptors, a related receptor issue that can be compared across the modalities. The humoral immune system is capable of producing at least 100 billion distinct receptors for new chemicals (Janeway \& Travers, 1999), which seems qualitatively different from human vision's three fixed cone receptors. However, "striking similarities" (Lane et al., 2002) of the immune system to olfaction have been noted, with olfaction also able to detect a practically infinite number of new distinct chemicals. Another sense of perceptual organ, its "impenetrability" to other systems, was touched on in the previous section and warrants future examination.

\section{Internal states}

Turning to internal states, the targets of representation in known sensory systems include properties that are unique to a modality, such as pitch in audition or temperature through touch, and properties that overlap, such as shape, distinguishable by both vision and touch, or spatial location in vision, audition, touch, and to some extent olfaction (see, e.g., Stein \& Meredith, 1993; Walk \& Pick, 1981). It is these parameters that are determinable by multiple modalities that provide the basis for cross-modal interactions. I argue that the immune system also shares targets of representation with the traditional modalities. The immune system, like many of the other modalities, is concerned with spatial location, because immune responses must be directed to the places that are under attack by foreign molecules and cells (antigens). An important shared parameter for the present theory is the distinction between self and nonself. The immune system must distinguish between self and nonself so as to attack foreign cells but leave its host cells unharmed. Likewise, vision and touch (including proprioception) help to evaluate where our own bodies begin and end. This forms the basis of body schema necessary for effective action. Establishing what is self is also essential for perceiving, not just acting, in order to be able to discount sensory changes due to our own bodies, as was noted earlier when introducing body schema. For instance, the perception of motion in the environment requires that motion on the retina due to our own head movement be discounted. Self versus nonself is also discussed in Visual imagery versus mindful meditation section. Detection of abnormality is a similar important shared parameter for mind-body interactions. The immune system can detect whether a cell is infected, but so can vision through cues of redness or swelling, or touch through heat, pain, and throbbing, or olfaction through an atypical smell. Thus, the immune system has shared targets of representation with other sense modalities, just like other sense modalities do with each other.

Since "internal states" can encompass virtually anything between the input and the output of a sensory system, it provides a vast territory for extracting commonalities between established modalities that can then be used for assessing new candidate modalities. Future developments may well be served by mining for major theoretical concepts that have arisen in the consideration of processing by sensory systems. As just one example, some approaches to the inner workings of perceptual systems have emphasized the problem-solving nature of computations that occur out of awareness (Rock, 1985), a view that dates back to Helmholtz (1866/2005). For instance, Rock discussed how the same figure seen in different orientations looks like a different object because of unconscious assignments of "top" and "bottom," used in conjunction with stored representations of objects previously learned. In the immune system, antigens encountered previously are recognized faster on subsequent exposures. Is it fair to say that this is unconscious learning and memory, like the unconscious inference ascribed to visual processing? Exploring the applicability of theoretical concepts that have developed in perception may be relevant for further evaluating the immune system's status as a modality.

\section{Function}

Analyzing next the function of sensory systems allows us to actually exclude part of the immune system from consideration. Surface barriers are sometimes considered part of the immune system because they provide a first line of defense against foreign objects. Saliva is an example of a surface barrier, 
because it contains enzymes that are antimicrobial (Beers, 2006). Thus, surface barriers also serve to protect the host, but they are not detectors. For the rest of the immune system, the purpose involves the detection of entities in the environment, just as for the recognized sense modalities. For the immune system, these entities include viruses, bacteria, fungi, tumor cells, and other infected or damaged cells (Beers, 2006).

However, it can be argued that real perceptual systems detect entities in the external environment, but the immune system is confined to those inside the body. Recall that definitions of sensory systems invoke external entities. While an inside-outside distinction seems like a qualitative difference, closer analysis suggests more of a continuum in range of operation. I suggest that the senses can be roughly ordered from near to far detection ability: immune system, taste (gustation), touch, olfaction, audition, and vision. The gustatory system seems to provide detection at a boundary between the inside and outside of the body, with taste immediately preceding the introduction of substances into the body and with receptors found down into the throat as well as on the tongue (see Behrens \& Meyerhof, 2011). ${ }^{3}$ Next, touch operates at the surface of the body, and objects can be discerned through active exploration (haptics) extending a little farther away within arms' reach (see, e.g., Klatzky \& Lederman, 2003). Touch may also extend inside the body, if pain is considered. The functional range of olfaction varies from very near the body, for evaluating potential food before ingestion, to conversational distances, for social purposes, to somewhat farther away, for detection of danger (Stevenson, 2010). The remaining modalities, audition and vision, are more distal senses that allow information from as far away as at least a couple of hundred meters to be detected. I suggest that the immune system covers the other side, and picks up where taste and touch leave off. Figure 2 illustrates the ranges of operation of these six detecting systems. Rather than being singled out from other sense modalities, the immune system seems more to complete the range for full coverage of detection at all distances. This fact alone may be a compelling reason to include the immune system as one of the major sensory systems.

\section{Output}

To complete the criteria with the remaining category of “output," Koffka (1935/1999) asked a now classic question

\footnotetext{
${ }^{3}$ Taste receptors have also been found in other places, including along the gastrointestinal tract and the testes. It has been suggested that their function may involve the assistance of digestion and metabolic processes (Behrens \& Meyerhof, 2011). These are not associated with perception of taste - at least not in any conscious, traditional sense of "taste" - and may provide another example of the blurring of the distinction between traditional sense modalities and internal body processes. See also note 2 .
}

in perception: Why do things look as they do? By extension, for audition, why do things sound as they do? What would be said of the immune system? Why do things _ as they do? The closest word we have is "feel," but it would not be quite accurate. Perceivers are familiar with the outputs of sensory modalities being accessible to conscious awareness, description, and deliberation. We are aware that we hear the baby, smell the skunk, feel his hand. We may be aware that we have a fever or lethargy, but we do not "perceive" the bacteria or cancer cell that has caused them, in the sense of conscious awareness of what the sensory system has detected. This is a notable difference, but not a deal breaker.

The output of the sense modalities can lead directly to action or knowledge without conscious awareness. The oftcited disorder "blindsight," in which patients see, but don't know they can see (Weiskrantz, 1986), is one example of dissociation in the visual modality. Visual information has gotten through, but patients have lost the conscious experience that used to accompany it. Familiar behavioral responses that precede conscious contemplation, such as withdrawing one's hand from a hot stove, provide other examples within touch. In olfaction, it has been reported that children can detect a biological, but not a step-, sibling, which might adaptively prevent sexual attraction to blood kin (Weisfeld, Czilli, Phillips, Gall, \& Lichtman, 2003); yet, does anyone say "I'm not interested because he smells like my brother"? That is, the output of olfactory perception in this situation is not conscious.

In addition to examples of perception without awareness, in vision research, a perceptual-motor distinction is well known. Goodale and Milner (1992) reported patients with damage within the ventral pathway who had lost the ability to see basic properties such as the orientation of an object, but were still able to accurately orient their hand to manipulate the object. Goodale and Milner argued that two previously discovered pathways, one projecting ventrally from the visual cortex to the temporal lobe and the other proceeding dorsally into the parietal lobe (Mishkin, Ungerleider, \& Macko, 1983), correspond to two visual systems, one serving perception and the other action. Besides clinical data, in undamaged observers there have been numerous reports of the motor system being immune to figural visual illusions. For instance, the presence of a surrounding frame that is off center can shift the perceived location of a small target, but participants point accurately to the target's true location (Bridgemen, 1993). Whether any of these findings implicate separate streams for conscious vision and motor vision has been called into question. The illusion dissociations have been criticized for having different stimuli for the different tasks, or for an egocentric system being used for motor responses but an exocentric system used for visual judgments (Dassonville \& Bala, 2004). Other interpretations for separate dorsal and ventral streams include object versus space ("what vs. where"; Mishkin 


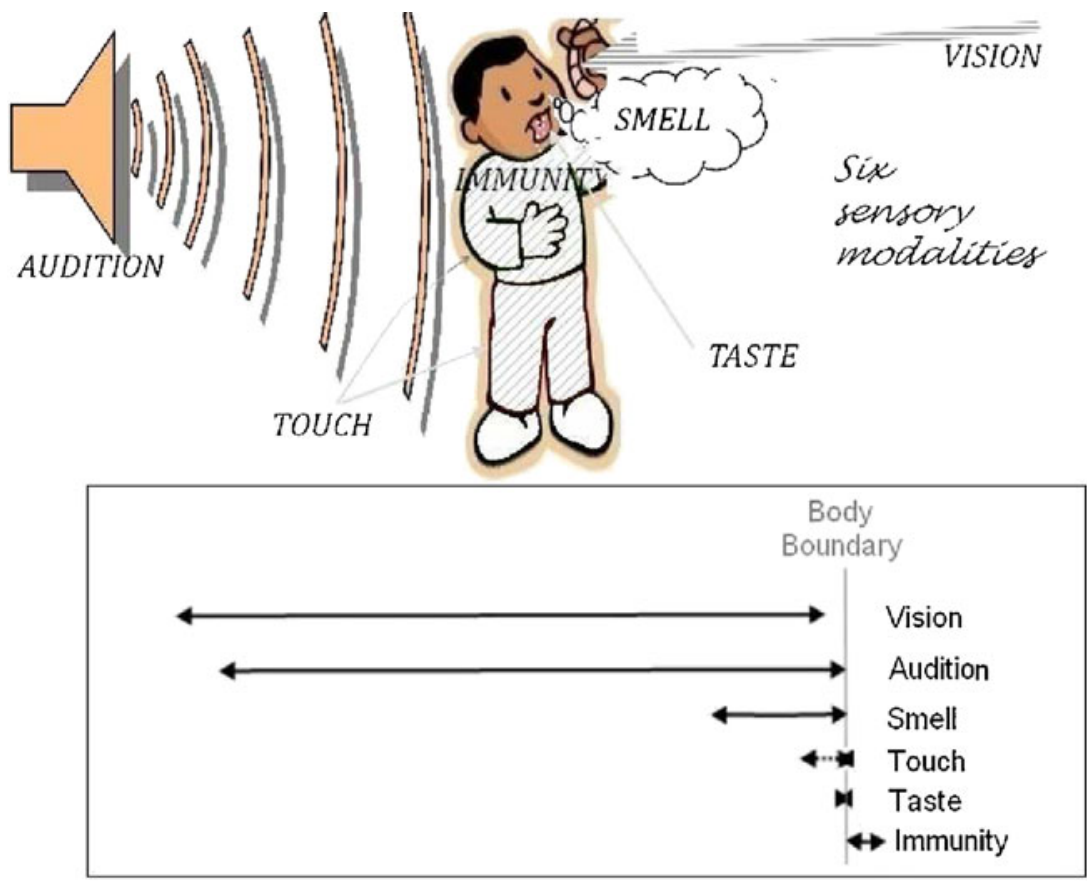

Fig. 2 Six sensory modalities. The illustration shows the relative range of function of each modality. Vision and audition can obtain information that is most distal from the body. Olfaction is next, allowing for information from relatively distant sources, such as detecting that something is burning in the kitchen, as well as for the appraisal of food close to the body before ingestion. Olfaction is followed by touch, which provides information at the surface of the body. Extending the arm allows information to be obtained a couple of feet in front of the head (shown as a dotted line in the box at the

et al., 1983) rather than perception versus action. However these debates resolve, it is difficult to avoid the accumulated data that action occurs to stimuli without observers' first experiencing and deliberating on them in the traditional sense.

The dissociability of perceptual outputs from conscious experience in other modalities implies that the immune system should not be ruled out as a perceptual modality, in spite of lack of awareness of what it detects. Reasons for the omission may include its early evolution and/or the lack of any adaptive benefit to having the detection of, say, a cancer cell available to general-purpose higher-order cognitive processing. The omission of conscious experience may contribute to unique aspects of the interaction between meditation/imagery and the immune system. (See Visual imagery versus mindful meditation section below.)

Before concluding discussion of output, a related, but not identical, issue should be addressed: whether the sense modalities each have a unique, characteristic kind of experience when stimulated. The same arguments apply for this issue; that is, the absence of such unique experience would not rule out the immune system from consideration as a sense modality because, as discussed, there are many examples of perception without any kind of experience. However, it may be worth pursuing whether the immune bottom), and how far touch extends inside the body may depend on whether perception of pain is considered. The gustatory system is at the interface of inside and outside the body, with taste receptors on the tongue and in the throat. Finally, the immune system (immunity) covers the entire inside of the body. Thus, while immunity is not one of "the Aristotle five", it completes the spatial range of detection of the sense modalities from far outside to all the way inside the body, covering all possible regions of interest to a detecting being

system does actually have a unique experience, even if the specific item that is detected is not experienced as such. Immune system activation, especially some of the proinflammatory cytokines, such as interleukin 6 , causes the experience of fatigue (Irwin, 2008). Certain clusters of experiences labeled "sickness behavior" (Dantzer \& Kelley, 2007; Kelley et al., 2003), which include fatigue, may comprise the immune system's unique sensory experience. This may pass a test of the doctrine of specific nerve energies, such that a sense modality's (here, the immune system's) characteristic experience (sickness behavior) occurs however that modality is stimulated, just as the experience of seeing occurs however the visual system is stimulated.

\section{Conclusion and caveats}

Consideration of the different categories of criteria suggested here, those of input, internal states, output, and function, suggests that the immune system may be a sensory modality, or at least should not be obviously excluded from such consideration. A few general issues about the preceding analysis should be noted.

First, perhaps these criteria are so general that any process would be included. Counterexamples to this 
argument would include processes of thinking and of motor actions, neither of which could be considered detectors when evaluating "function." Another concern is that there is an inherent circularity to the reasoning, because at the same time that the immune system was being evaluated for meeting the criteria, the criteria themselves were being evaluated for their usefulness. For example, although spatially contiguous receptors have been mentioned historically as part of sensory systems (input: organ of perception), they were rejected here as not being a necessary criterion. This is at present unavoidable because the criteria extracted are only candidates, not universally agreed-upon, necessary and sufficient conditions for being a sense modality. Evaluation of the immune system might even force criteria to become more explicit and refined. An example of this might be recasting "external" detection as part of the definition or function of sensory systems as meaning detection of "nonself", rather than the space outside of the outer physical boundary of the body.

It should also be asked: If the immune system fits the criteria of a perceptual modality so well and, moreover, is so important as to complete the range of stimuli detectable, as I have suggested here, why has the immune system not been included before? The number of distinct modalities that have been suggested to exist ranges from only one to at least 17 (Keeley, 2002; see also Fish, 2010). The original five bequeathed by Aristotle - sight, sound, touch, taste, and smell-appear to remain the most widely used assumption in perception theorizing (e.g., Laming, 1988). It is not surprising that modalities whose outputs are open to conscious introspection would be those that were noticed first. The methods of modern science later revealed the more hidden systems, such as an older visual system mediated by the superior colliculus that does not usually reach conscious experience, and an accessory olfactory system believed to be involved in pheromone detection (Keller, Baum, Brock, Brennan, \& Bakker, 2009). All of the original modalities have components. The modality summarized as "touch" or the "cutaneous system" in perception texts (Goldstein, 2006) consists of the very distinct properties of haptics (recognition of spatially extended objects through active exploration), proprioception (localizing the position of body parts), skin sensations of temperature, touch, vibration, and texture, and the perception of pain. Some researchers have considered components to be different modalities (Klatzky \& Lederman, 2003), and others have been content to keep the original framework and to consider these subsystems of an original modality. It may no longer matter to most researchers what their systems and components are called, since the basic framework has - up to now-been sufficient for most research agendas. Note that the immune system also has different subsystems, including, as noted earlier, innate and acquired immunity, with the latter consisting of humoral and cellular immunity. Without a conscious subsystem, it is easy to understand why the immune system was overlooked in Aristotle's original framework.

Finally, note that this section on the sense modalities was not intended as a complete, systematic analysis of the claim that the immune system is a sensory system or of how its properties compare to the Aristotle five. Instead, it was to suggest that there is sufficient reason for considering its status as a perceptual modality, so that a model of cross-modal interaction can proceed. Progress may come now as much from allowing a cross-modal vision-immune system adaptation framework to proceed as from further analysis of whether the immune system meets abstract criteria for a being a sense modality.

\section{Visual imagery versus vision}

The cross-modal adaptation suggested for mind-body healing results from a conflict between visual imagery and the purported modality of the immune system, whereas for prism adaptation, the conflict is between vision and proprioception. In addition to the presumption that the immune system is a modality, the theory of mind-body healing as cross-modal adaptation also assumes that visual imagery can substitute for vision. Can visual imagery be used instead of vision in crossmodal interactions, specifically in adaptation? It was noted in the early section on the relevance of perception to guided imagery and mindfulness that visual imagery appears to be functionally equivalent to real vision. But that does not show that visual imagery can duplicate the effects of externally driven real vision in all circumstances. Imagery has also been found to sometimes have coarser representations than the detail available in a real image (Michelon \& Koenig, 2002). Adaptation has unique requirements: a registered discrepancy between the two modalities with respect to the same parameter, which can trigger the detection of an error, such as occurs with vision and proprioception about the location of a target, which then leads to prism adaptation. If it can be shown that visual imagery can drive the discrepancy between two modalities in an accepted case of cross-modal adaptation then this would provide firmer grounds for its use in crossmodal adaptation involving the immune system.

Finke (1979) assessed the ability of visual imagery to produce "prism" adaptation in which imagery of a displacement would replace the displacement ordinarily produced by a prism. One group of participants looked through a wedge prism and pointed at a target; they were unable to see the position of their arm or hand until their arm movement was 
complete, which is a standard "terminal" prism exposure procedure frequently used in prism adaptation experiments. A second group also looked through the prisms, but never saw the location of their arm or hand; instead, they were asked to visualize that their hand had arrived at a location to the side of where their hand really was (and felt like it was). This simulated the visual position that the first group would experience as a result of the prism. A final control group looked through the prism and pointed, but they received neither visual feedback nor imagery instructions. Following several minutes of exposure to the appropriate regimen, all groups were tested both for any negative aftereffect in pointing following removal of the prism and any transfer to the unexposed hand.

In ordinary prism adaptation, the negative aftereffect refers to participants pointing in the direction opposite the displacement following removal of the prisms (Welch, 1978). At least several minutes of exposure to the prism produces adaptation that also corrects any initial pointing errors; the change continues following prism removal, even when participants know that they are no longer looking through a prism, and is therefore manifested as an error in the direction opposite the original error. For example, an initial displacement of vision to the left produces pointing that is too far to the left of a target while looking through the prism. With adaptation, pointing will move rightward until it coincides with the target. The rightward shift remains, and if the visual displacement of the prism is removed, participants will be observed now to point too far to the right of the target. All testing is typically done without the subject getting visual feedback. In addition, in terminal exposure, partial intermanual transfer is expected from the pointing hand to the hand not used during exposure. This is because in terminal exposure, the visual-proprioceptive conflict leads to a shift in the felt direction of gaze ("visual" change) in addition to the shift in felt arm position (proprioceptive change) produced with other types of prism exposure. A shift in felt arm position does not transfer to the other arm, but a shift in felt eye position will manifest as a pointing change for any test involving vision, including pointing to a visual target with the other arm (Harris, 1965). Finke found that the real-prismexposure condition produced about $40 \%$ total adaptation, which is within the range of prism adaptation studies. He also found that participants in the control condition did not show any change in pointing, as expected. In the imagery condition, participants showed about half of the adaptation shown by the participants in the prism-exposure condition. Participants who reported more vivid imagery showed greater change. Comparable partial transfer to the unexposed arm was found in both the imagery and prism conditions. Expectation as the cause for the change in pointing was additionally ruled out in a subsequent experiment in which participants were misled about where they should be expected to point. ${ }^{4}$ Finke concluded that visually imagined errors of movement are functionally equivalent to the real, seen counterpart.

Overall, the adaptation study suggests that imagery may be a less potent stimulus than actual vision, but that qualitatively it can induce conflict with proprioception that is usable for detecting the errors that lead to adaptation, just as in actual vision. Note that it would not have been necessary for imagery to be substitutable for vision in prism adaptation for it to be so in the immune system - the immune system may have unique properties especially reachable by imagery in particular - but it would be unfortunate if it turned out that the immune system were the only modality in which visual imagery could stand in for vision in crossmodal interactions. This does not appear to be the case.

\section{Visual imagery versus mindful meditation}

The preceding discussions have emphasized visual imagery as the mind-based intervention for healing. Meditation is also significant from the perspective of perception research. Recall that mindful meditation calls for an almost unnatural attention and hypervigilance to the object of meditation, such as the body in body scanning or sounds or the breath or thoughts: "If [awareness] moves off the breath a hundred times, then you just calmly bring it back a hundred times, as soon as you are aware of not being on the breath" (Kabat-Zinn, 2005, p. 65). In the present view, the role of mindful meditation in the adaptation process is to ensure that the conflict is of sufficient strength to be effective, often by heightening the salience of one of the modalities. This has arguably been a hidden assumption of the present cross-modal adaptation theory.

Consider the role that attention may play in adaptation from the perceptual adaptation literature. Canon (1970) formulated the "directed attention hypothesis," in which he argued that when two modalities are in conflict, the one that changes is the one that is not attended. He had visual and auditory modalities provide conflicting information about the location of an object. During 20 min of exposure to the conflict, the object moved around, and the participants were

\footnotetext{
${ }^{4}$ Note that a very stringent test of adaptation that would verify that observed changes in pointing to locations of targets really reflect adaptation rather than a familiar motor response (see Bedford, 1999) would require more tests than the negative aftereffect. These include a battery of tests that more directly show that the felt position of the arm has actually shifted and/or that the felt direction of the eyes has shifted. However, the majority of prism adaptation experiments have used only the negative aftereffect as evidence of adaptation, and the Finke (1979) study actually went a step farther by testing intermanual transfer; this begins to get more directly at the components of actual adaptation.
} 
instructed either to keep pointing to the moving visual target and ignore audition or to point to the auditory location while ignoring vision (but keeping their eyes open). He found that following the visual attention instructions, adaptation was entirely within the auditory modality, whereas following the auditory attention instructions, adaptation in the visual modality was increased. Thus, it appears that the unattended modality is the one that changes in crossmodal conflicts, despite the seeming nonadaptiveness of such a conflict resolution (that is, the modality that should change is the one determined to be at fault, not the one that happens to escape attention; Bedford, 2007a).

Redding (1979) has since argued that invoking the concept of "attention" may not be necessary and that what determined which modality changed could be viewed more simply. He suggested that the different conditions in the Canon (1970) experiment specified different sources of information that control the task during exposure and that more precisely the noncontrolling source of information (noncontrolling modality), not the "unattended" modality, is the one that is recalibrated. The noncontrolling modality changes because it would be too disruptive to functioning to change the modality doing the controlling during the task. In visual-proprioceptive conflicts, he and Wallace (Redding \& Wallace, 1990, 1997) used the example of looking at your watch to check the time. Proprioception is used to guide the action, and visual feedback occurs only at the end of the movement. In such cases, in which visual feedback occurs late (as in terminal exposure), proprioception is the guiding modality, and vision would be expected to change. That is contrasted with watching one's arm continuously to point to a target; in this case, vision is the guiding modality, and proprioception should change. Redding and Wallace (1990) confirmed their hypothesis in an elegant experiment in which they systematically increased the delay of visual feedback and showed that that the amount of adaptation within the visual modality systematically increased.

Whether attention is a meaningful and relevant construct for explaining which modality changes in perceptual adaptation has never been fully resolved. However, it is important to note that the same objections can be made to the use of attention in body scan and mindful meditation. When meditators feel a part of the body while doing the body scan exercise, it can be argued that they too are simply using proprioception as a source of information, and that "attention" is more of a shortcut descriptive term rather than an explanation. In mindful meditation, as well as in known examples of cross-modal adaptation, what precisely is meant by "attention" and whether it is being used in an information-processing sense, such as using a limitedcapacity resource (see Redding, 1979), needs further work. For the present purposes, whether the most precise description proves to be attended/unattended modality (Canon, 1970), controlling/controlled modality (Redding, 1979), or guiding/guided modality (Redding \& Wallace, 1990, 1997), the experimental findings suggest that enhanced proprioceptive signals lead to greater visual change in visual-proprioceptive conflicts, enhanced auditory signals lead to greater visual change in auditory-visual conflicts, and enhanced visual signals lead to changes in the remaining conflicting modalities.

Thus, in the present view, the role of mindful meditation in perceptual adaptation is generally to heighten the salience, or increase the signal strength, of the modality that is the focus of the meditation. The body scan exercise should have an effect similar to that of the arm vibration that was discussed earlier; it enhances the proprioceptive signal, which leads to a greater change in a different modality. In mind-body healing, the unusual single-minded focus on one sense modality that meditation causes would greatly facilitate recalibration of the other modalities - such as the immune system. It also should serve to prevent the intrusion of inappropriate imagery that would undermine the imagery-induced cross-modal conflict, as well as generally preventing other dilutions of training with irrelevant images. The single-minded attention therefore also allows for concentrated training that should facilitate the cross-modal effects.

Consequently, in the present view, imagery by itself, without meditation, should be sufficient to bring about healing, provided that appropriate vivid images can be manufactured without such assistance. Moreover, the combination of imagery and mindful meditation should be especially effective. This is in contrast to Kabat-Zinn, whose position on the relation between imagery and mindfulness is that "in order to be effective for healing, we believe that the use of visualization and imagery needs to be embedded in a larger context, one that understands and honors non-doing and non-striving" (Kabat-Zinn, 2005, p. 178).

Psychological interventions typically use multiple techniques together, including imagery, meditation, relaxation, and sometimes hypnosis (Eremin et al., 2009; Kabat-Zinn et al., 1998; Walker et al., 1999; see also Collins \& Dunn, 2005, and Miller \& Cohen, 2001, for discussions), making it difficult to assess the separate contributions of each component. Bedford (2011; Bedford \& Peterson, 2010) found visual imagery to be effective on pain and skin disorders (in high visualizers) when preceded only by a brief modified body scan exercise of mindfulness mediation, but by no other intervention. However, that work did not look at imagery by itself. Spanos et al. (1988, Exp. 3) compared visual imagery suggestions following hypnosis to visual imagery without hypnosis and found imagery alone to be just as effective at removing warts. Hypnosis is not 
the same as mindful meditation, but it may serve a similar role in perceptual adaptation of changing the relative information strengths of different modalities and/or the overall strength of conflict. Consistent with this idea are findings that hypnotic suggestions of anesthesia to the hand or eye muscles in prism adaptation change which modality adapts and/or reduce adaptation (Garrett \& Wallace, 1975; Wallace, 1980; Wallace \& Fisher, 1984). As a side note, it is interesting to ask whether hypnotic suggestions would be capable of decreasing as well as increasing the salience of modalities, since mindful meditation always increases the salience of the target of meditation. Overall, hypnosis may work similarly in mind-body adaptation as in prism adaptation. It has also been found that imagery added to music or relaxation seemed to cause greater immune response, as measured by concentrations of IgA in saliva, than did music or relaxation alone (Gregerson, Roberts, \& Amiri, 1996; Rider et al., 1990). Controlled scientific studies will clearly also be needed to test the reverse situation: the sufficiency of imagery and the incremental effect of meditation and relaxation.

In the present view, visual imagery without mindful meditation should be capable of leading to adaptation, including adaptation of the immune system, but how about mindfulness mediation without visual imagery? In the present view, simply heightening the salience of a particular modality, which is argued to be the key ingredient in mindful meditation, is insufficient for producing adaptation. Adaptation requires a conflict. However, mindfulness exercises may often have built into them implicit cross-modal conflicts. Kabat-Zinn says of the body scan meditation that when a practicer leaves each body part mentally behind, he or she is also leaving behind "any of the thoughts and inner images you may have found associated with it" (Kabat-Zinn, 2005, p. 77). He pointed out that people may have negative thoughts about parts of the body that can then change when one is allowed to actually experience what those parts feel like. Thus, mindfulness may lead to the conflicts required to obtain adaptation, even when explicit instructions to invoke specific visual images in healing studies are absent. ${ }^{5}$

In addition to further research on the separate effectiveness of imagery and mindfulness, investigations of other perception-based aspects of meditation are also needed. One aspect in particular is an implication of attention

\footnotetext{
${ }^{5}$ Other positive benefits of mindful mediation for wellbeing that have been reported, such as inner calm and relaxation, could result from these or other aspects of the meditation. These benefits are not in the domain of the present theory. In the present theory, actual physical healing results from cross-modal adaptation, as discussed, and the increased signal strength provided through mindful meditation (along with any resulting cross-modal perceptual conflicts) is the aspect of mindfulness that is relevant for adaptation.
}

other than increase in modality signal strength. Attention is typically what we do when perceiving the world to bring it into conscious awareness (Velmans, 1991). For cases in which attention-rich meditation accompanies imagery of immune cells, are we somehow assisting a sense modality - the immune system - whose output is typically not open to consciousness to be more like its visual and auditory siblings?

Another pursuit concerns specifically the body scan exercise, in which the body is the target of meditation. This exercise raises once again the important issue of distinguishing self from nonself. From a perception perspective, the body scan exercise hones awareness of the body schema, the representation of the body with its positions and boundaries. The body scan exercise serves to reinforce, over and over, the current boundaries of the body, attending to where we begin and where we end, distinguishing self from nonself. What is regarded as self can change, as reflected by inanimate objects being made a part of the body schema (Botvinick \& Cohen, 1998; Maravita \& Iriki, 2004), as well as by changes to the body envelope that must occur with growth (Bedford, 2007b). The reverse can also occur, in which real parts of the body are denied ownership (Sacks, 1985). There is a striking parallel in the immune system. For half a century in the field of immunology, a central role of the immune system has been considered to be to distinguish self from nonself (Burnet \& Fenner, 1949; but see Tauber, 2010). Without this ability, the immune system would not know what is safe and what to attack. Like the perceived body envelope, this too is changeable. Autoimmune illnesses were discussed in a previous section as resulting from an error in the immune sensory modality. They also reflect failure to tolerate the "self," a very literal meaning to being one's own worst enemy. The full potential of this parallel has yet to be realized. It is tempting to suppose that the body scan exercise may be especially useful in autoimmune disorders, such that continued emphasis on the correct external and internal boundaries of self through the modality of proprioception, and perhaps vision, would conflict with, and therefore change, any immune system errors about the self. Although these connections to perception are speculative, continued perception-based leads are important and dialog between perception and meditation researchers is needed to progress our understanding further.

\section{Oh, my aching back}

The previous three sections examined assumptions of the present adaptation theory of mind-body healing. Other views of mind-body healing are now considered briefly, beginning with singling out the special topic of pain. Is an immune-visual cross-modal adaptation analysis applicable 
to pain, or is the "subjectivity" of pain a simpler and more fitting explanation? This is an important question to consider, because mind-body interventions of guided imagery and mindful meditation appear to be very successful with pain (e.g., Baird et al., 2010; Ball et al., 2003). It may appear both that the immune system is not relevant for pain and that visual imagery of pain (or its absence) isn't sensible. If true, these factors would limit the scope of the present theory. However, some of the earliest neuropeptides shown to be made not just in the head, but in the immune system, were endorphins, which modulate pain, and the opioid receptors remain one of the best studied classes of neural receptors that are also found in the immune system; later, macrophages in the immune system were shown to be a source of substance $\mathrm{P}$, also a brain chemical involved in pain (Blalock, 2005; Blalock \& Smith, 2007). Currently, many levels of interaction between the immune system and pain thresholds in acute and chronic pain are recognized (Ren \& Dubner, 2010). The immune system can clearly be involved in the regulation of pain.

Imagery in pain is not as straightforward as imagery in skin disorders. One can see, either literally or in one's mind's eye, skin as red or normally colored, as scaly or smooth, as bumpy or flat. It is intriguing to contemplate precisely what visual images are involved with pain. Do people form an image of themselves hunched over? Or a hand on their aching head, or the inability to move a joint? Imagery instructions sometimes have included relatively specific direction, such as imagining warm sunshine soaking into painful areas, but often they are or include instructions that are unrelated or general, such as to visualize a pleasant scene, imagine being healthy and strong, imagine anything the practicer wants, and emerge with a sense of wellbeing (Carrico et al., 2008; Kwekkeboom et al., 2008; Menzies \& Kim, 2008; Menzies et al., 2006). Studies typically do not investigate what participants actually do after receiving instructions. In other cognitive domains, such as blindfold chess, imagery is reported to become more abstract as people become experts (Hearst \& Knott, 2009), raising the possibility that abstract images that are effective on pain are being developed during the extended practice that mindfulness training entails. Indeed, one advantage of using imagery would be its to conjure images not otherwise possible with real vision. To the extent that "perception of pain" is itself a modality, the existence of cross-modal conflicts between vision and pain, in addition to those of vision and the immune system, may also contribute to the particularly effective pain control reported with mind-body interventions.

Attributing successes instead to the subjectivity of pain is not very compelling. Labeling pain as subjective (Aydede, 2010; Charlton, 2005; Clark, Yang, Tsui, Ng, \& Bennett Clark, 2002; Kumar, Tandon, \& Mathur, 2002) is an inappropriate dismissal, because pain is mediated by chemicals and neural responses every bit as real as the chemicals that mediate other physical manifestations. The casual view that pain is all in one's head may owe less to science and more to the observation that pain is of no consequence except to the sufferer.

\section{Is psychology lagging behind?}

Psychoneuroimmunology has been rapidly advancing knowledge of brain-immune system mechanisms. For instance, stress causes an increase in CRH (corticotropin-releasing hormone), which leads to immune system depression, a process that can by modulated by the "relaxing" neurotransmitter GABA, or $\gamma$-aminobutyric acid (see Irwin, 2008). Contributions in psychology appear to be lagging behind. Besides the view that psychological manipulations work only on subjective symptoms, it has been argued that psychological interventions such as imagery only work on medical conditions by creating an expectation of success (Kirsch, 1985). There is empirical evidence against this claim; see, for example, Achterberg and Lawlis (1987), Simonton et al. (1992), and Spanos et al. (1990). But, more importantly, the idea still awaits being turned into a theory. Why, how, and when would expecting something to succeed make it happen? I have been expecting for months that a manuscript will be accepted, but it has not. Similarly, stress reduction/relaxation has been offered as the explanation of successful psychological methods, such as meditation, on health. Stress has been shown to affect the immune system, but a psychological theory that does not hide behind chemokines or cortisol has yet to be detailed. Psychological stress is the feeling that the external demands are exceeding one's resources and capacity to meet the demands. Why, how, and when changing that feeling leads to improvement requires explication before it can be examined, and in order to avoid the circularity of stress as an explanation.

One of the few psychological theories of mindfulness mediation has proposed that the mechanism of healing is "reperceiving" (S. L. Shapiro, Carlson, Astin, \& Freedman, 2006). Although this theory uses the word "perceiving," the authors mean it instead figuratively, as a "significant shift in perspective" (p. 377). They suggest that intentionality and attending with openness leads to reperceiving, which is a "metamechanism of action," which in turn leads to at least four further mechanisms (self-regulation; values clarification; cognitive, emotional, and behavioral flexibility; and exposure) that lead to change and a positive outcome. It is difficult to know how to compare this model with the present perspective. Finally, reviews have noted that "not a lot is written on why guided imagery is often helpful" (Utay \& Miller, 2006). Psychological theories are essential. 
Without them, progress is limited. Intriguing experiments in mind-body healing, such as an investigation of the half-life of imagery and meditation (Collins \& Dunn, 2005), are too infrequent.

\section{A call to action}

In contrast, recognizing that the immune system is a perceptual modality and that mind-body interaction reflects resolution of conflicting perceptual modalities suggests new avenues of inquiry. For treatment, the theory suggests that real vision will be more effective for healing than imagined vision in instances in which real vision can provide the appropriate input. Using the technique in which a normal limb is reflected in a mirror to appear as two normal limbs (Ramachandran et al., 1999) may be a useful treatment for skin disorders on an arm or leg. As noted earlier, the theory makes the counterintuitive prediction that chemotherapy agents that lead to signs of grave illness detectable by sense modalities, such as hair loss, will lead to greater improvements when all else is held constant. With the identification of conflict as a key ingredient, more tailored interventions can be devised for each disorder, rather than throwing all possible mind-based manipulations into a treatment or experiment and hoping the procedure works. The theory also maintains that visual-immune system conflicts can produce measurable change in the visual modality as well as the immune modality; such a resolution should be sought when mindful meditation/imagery seems to fail to produce change. This examination may also lead to treatments that shift the balance of change back to the immune system. Finally, identification of those who may benefit most from mindfulness/imagery treatment may be possible by assessing visual imagery ability on standardized perceptual imagery tests (Marks, 1995).

In addition to treatment possibilities, the new approach also suggests an interesting question. Ethical considerations aside, can imagery be used to make health worse as well as better? Moreover, the approach calls for new tests of whether body scan is particularly effective in autoimmune illnesses and whether mind-body interactions are best used in instances in which the immune system has made an error; for the development of techniques to improve error detection for immune-vision or immune-touch conflicts, analogous to the techniques in prism adaptation (which will eventually lead to more efficient treatment); for careful assessment of the separate contributions of imagery, body scanning, attention to breathing, and attention to thoughts; for investigation of the content of imagery for pain and internal organs and how they change over time; and for exploration of instances in which the immune system normally cooperates with vision, hearing, touch, olfaction, and taste, because in perception, cross-modal cooperation occurs as well as cross-modal conflict (Walk \& Pick, 1981). Further scrutiny is also warranted on other occurrences that may further blur the distinction between perception and health, including physical symptoms such as vomiting following perceptual conflicts between vision and the vestibular system, and the presence of taste receptors deep inside the body that assist digestion and metabolism (see notes 2 and 3 ). Bridging the gap between psychological concepts and immune and brains mechanisms will likewise be important.

The theory also has consequences for perception research. These issues are largely beyond the scope of the present article, but they include investigation of unnaturally sustained attention and of whether the body scan exercise of mindful meditation facilitates adaptation to visualproprioceptive conflict in prism adaptation in the same way it does for visual-immune system conflict.

It takes a village to raise an idea, and the joint effort of multiple laboratories in cognition, neuroscience, and medicine will be required to tap the full potential of the present theory that mind-body healing is perceptual cross-modal adaptation. Moreover, allowing the immune system to take its rightful place as a sensory modality should engage perception scholars to extend a century of research on sensory systems in this very new direction for the field of perception. And likewise, a century of perception research will now be applicable to the immune system.

Author note This work was supported by a mini-grant from the Social and Behavioral Sciences Research Institute (SBSRI) at the University of Arizona. Thanks go to the faculty and students at the Psychology Department of Ramapo College of New Jersey, especially Robert Becklen and Joe Cataliotti, for helpful and inspiring discussions during a visit while on sabbatical; Joel Lachter at NASA/ Ames for a discussion point about consciousness and attention; and Robert Rescorla at the University of Pennsylvania for discussion of early conditioning work.

\section{References}

Achterberg, J. (1985). Imagery in healing: Shamanism and modern medicine. Boston: New Science Library, Shambhala.

Achterberg, J., \& Lawlis, G. (1987). Imagery of disease. Champaign, IL: Institute for Personality and Ability Testing.

Ader, R., \& Cohen, N. (1975). Behaviorally conditioned immunosuppression. Psychosomatic Medicine, 37, 333-340.

Aydede, M. (2010). Pain. In E. N. Zalta (Ed.), The Stanford encyclopedia of philosophy. Stanford, CA: Stanford University, Metaphysics Research Lab. Retrieved from http://plato.stanford. edu/archives/spr2010/entries/pain/

Baer, R. A. (2003). Mindfulness training as a clinical intervention: A conceptual and empirical review. Clinical Psychology: Science and Practice, 10, 125-143. doi:10.1093/clipsy/bpg015

Baird, C. L., Murawski, M. M., \& Wu, J. (2010). Efficacy of guided imagery with relaxation for osteoarthritis symptoms and medica- 
tion intake. Pain Management Nursing, 11, 56-65. doi:10.1016/j. pmn.2009.04.002

Ball, T. M., Shapiro, D. E., Monheim, C. J., \& Weydert, J. A. (2003). A pilot study of the use of guided imagery for the treatment of recurrent abdominal pain in children. Clinical Pediatrics, 42, 527-532. doi:10.1177/000992280304200607

Banks, M. S. (1988). Visual recalibration and the development of contrast and optical flow perception. In A. Yonas (Ed.), Perceptual development in infancy (pp. 145-196). Hillsdale, NJ: Erlbaum.

Bedford, F. L. (1993a). Perceptual and cognitive spatial learning. Journal of Experimental Psychology. Human Perception and Performance, 19, 517-530. doi:10.1037/0096-1523.19.3.517

Bedford, F. (1993b). Perceptual learning. In G. H. Bower (Ed.), The psychology of learning and motivation: Advances in research and theory (Vol. 30, pp. 1-60). Hillsdale, NJ: Erlbaum.

Bedford, F. L. (1995). Constraints on perceptual learning: Objects and dimensions. Cognition, 54, 253-297. doi:10.1016/0010-0277(94) 00637-Z

Bedford, F. L. (1999). Keeping perception accurate. Trends in Cognitive Sciences, 3, 4-11. doi:10.1016/S1364-6613(98)01266-2

Bedford, F. L. (2001). Towards a general law of numerical/object identity. Cahiers de Psychologie Cognitive/Current Psychology of Cognition, 20, 113-175.

Bedford, F. L. (2004). Analysis of a constraint on perception, cognition, and development: One object, one place, one time. Journal of Experimental Psychology. Human Perception and Performance, 30, 907-912. doi:10.1037/0096-1523.30.5.907

Bedford, F. L. (2007a). Can a space-perception conflict be solved with three sense modalities? Perception, 36, 508-515. doi:10.1068/ p5632

Bedford, F. L. (2007b). Is prism adaptation "for" growth? Perceptual and Motor Skills, 105, 351-354.

Bedford, F. (2011). L. Perception and well being: Imagery and mindful mediation for chronic pain and skin conditions in a college population. Manuscript under review.

Bedford, F. L., \& Peterson, S. (2010). Effect of visual imagery and perceptual mindfulness on physical healing. Boston: Poster presented at the meeting of the Association for Psychological Science (APS).

Beers, M. H. (2006). The Merck manual of diagnosis and therapy (18th ed.). Rahway, NJ: Merck.

Behrens, M., \& Meyerhof, W. (2011). Gustatory and extragustatory functions of mammalian taste receptors. Physiology and Behavior. doi:10.1016/j.physbeh.2011.02.010

Behrmann, M., Moscovitch, M., \& Winocur, G. (1994). Intact visual imagery and impaired visual perception in a patient with visual agnosia. Journal of Experimental Psychology. Human Perception and Performance, 20, 1068-1087. doi:10.1037/00961523.20.5.1068

Berg, J. M. (2002). Sensory systems. In J. M. Berg, J. L. Tymoczko, \& L. Stryer (Eds.), Biochemistry (5th ed., chap. 32). New York: W. H. Freeman.

Blalock, J. E. (1984). The immune system as a sensory organ. Journal of Immunology, 132, 1067-1070.

Blalock, J. E. (1989). A molecular basis for bidirectional communication between the immune and neuroendocrine systems. Physiological Reviews, 69, 1-32.

Blalock, J. E. (2005). The immune system as the sixth sense. Journal of Internal Medicine, 257, 126-138. doi:10.1111/ j.1365-2796.2004.01441.x

Blalock, J., \& Smith, E. M. (2007). Conceptual development of the immune system as a sixth sense. Brain, Behavior, and Immunity, 21, 23-33. doi:10.1016/j.bbi.2006.09.004

Botvinick, M., \& Cohen, J. (1998). Rubber hands "feel" touch that eyes see. Nature, 391, 756. doi:10.1038/35784
Bresler, D. E., \& Rossman, M. L. (2004). Fundamentals of interactive guided imagery. Awareness Press.

Bridgemen, B. (1993). Separate visual representations for perception and for visually guided behavior. In S. R. Ellis, M. K. Kaiser, \& A. C. Grunwald (Eds.), Pictorial communication in virtual and real environments (pp. 316-327). Philadelphia: Taylor \& Francis.

Burnet, F. M., \& Fenner, F. (1949). The production of antibodies (2nd ed.). Melbourne: Macmillan.

Canon, L. K. (1970). Intermodality inconsistency of input and directed attention as determinants of the nature of adaptation. Journal of Experimental Psychology, 84, 141-147. doi:10.1037/h0028925

Cardinali, L., Frassinetti, F., Brozzoli, C., Urquizar, C., Roy, A. C., \& Farnè, A. (2009). Tool-use induces morphological updating of the body schema. Current Biology, 19(12), 478-479. doi:10.1016/j.cub.2009.05.009

Carrico, D. J., Peters, K. M., \& Diokno, A. C. (2008). Guided imagery for women with interstitial cystitis: Results of a prospective, randomized controlled pilot study. Journal of Alternative and Complementary Medicine, 14, 53-60. doi:10.1089/acm.2007.7070

Chapman, H. L., Eramudugolla, R., Gavrilescu, M., Strudwick, M. W., Loftus, A., Cunnington, R., et al. (2010). Neural mechanisms underlying spatial realignment during adaptation to optical wedge prisms. Neuropsychologia, 48, 2595-2601. doi:10.1016/ j.neuropsychologia.2010.05.006

Charlton, J. E. (2005). Pain measurement in humans (chap. 7). In J. E. Charlton (Ed.), Core curriculum for professional education in pain. Seattle: IASP Press.

Clark, W. C., Yang, J. C., Tsui, S.-L., Ng, K.-F., \& Bennett Clark, S. (2002). Unidimensional pain rating scales: A multidimensional affect and pain survey (MAPS) analysis of what they really measure. Pain, 98, 241-247. doi:10.1016/ S0304-3959(01)00474-2

Collins, M. P., \& Dunn, L. F. (2005). The effects of meditation and visual imagery on an immune system disorder: Dermatomyositis. Journal of Alternative and Complementary Medicine, 11, 275284. doi:10.1089/acm.2005.11.275

Coren, S., Ward, L. M., \& Enns, J. T. (1999). Sensation and perception (5th ed.). San Diego: Harcourt Brace.

Creswell, J. D., Myers, H. F., Cole, S. W., \& Irwin, M. R. (2009). Mindfulness meditation training effects on CD4+ T lymphocytes in HIV-1 infected adults: A small randomized controlled trial. Brain, Behavior, and Immunity, 23, 184-188. doi:10.1016/j. bbi.2008.07.004

Dantzer, R., \& Kelley, K. W. (2007). Twenty years of research on cytokine-induced sickness behavior. Brain, Behavior, and Immunity, 21, 153-160. doi:10.1016/j.bbi.2006.09.006

Dassonville, P., \& Bala, J. K. (2004). Perception, action, and Roelofs effect: A mere illusion of dissociation. PLoS Biology, 2, e364.

Dawkins, R. (1996). Climbing Mount Improbable (1st ed.). New York: Norton.

de Cheveign'e, A. (2001). The auditory system as a separation machine. In J. Breebaart, A. J. M. Houtsma, A. Kohlrausch, V. F. Prijs, \& R. Schoonhoven (Eds.), Physiological and psychophysical bases of auditory function (pp. 453-460). Maastricht, The Netherlands: Shaker Publishing BV.

Editors of Prevention Magazine Health Books. (2003). The doctor's book of home remedies (Revth ed.). New York: Bantam.

Ellis, B. J. (1992). The evolution of sexual attraction: Evaluative mechanisms in women. In J. H. Barkow, L. Cosmides, \& J. Tooby (Eds.), The adapted mind: Evolutionary psychology and the generation of culture (pp. 267-288). New York: Oxford University Press.

Elomaa, M. M., de Williams, A. C. C., \& Kalso, E. A. (2009). Attention management as a treatment for chronic pain. European Journal of Pain, 13, 1062-1067. doi:10.1016/j. ejpain.2008.12.002 
Eremin, O., Walker, M. B., Simpson, E., Heys, S. D., Ah-See, A. K., Hutcheon, A. W., et al. (2009). Immuno-modulatory effects of relaxation training and guided imagery in women with locally advanced breast cancer undergoing multimodality therapy: A randomised controlled trial. Breast, 18(1), 17-25. doi:10.1016/j. breast.2008.09.002

Farah, M. J. (1988). Is visual imagery really visual? Overlooked evidence from neuropsychology. Psychological Review, 95, 307 317. doi:10.1037/0033-295X.95.3.307

Fernros, L., Furhoff, A.-K., \& Wändell, P. E. (2008). Improving quality of life using compound mind-body therapies: Evaluation of a course intervention with body movement and breath therapy, guided imagery, chakra experiencing and mindfulness meditation. Quality of Life Research, 17, 367376. doi:10.1007/s11136-008-9321-x

Finke, R. A. (1979). The functional equivalence of mental images and errors of movement. Cognitive Psychology, 11, 235-264. doi:10.1016/0010-0285(79)90011-2

Finke, R. A., \& Schmidt, M. J. (1977). Orientation-specific color aftereffects following imagination. Journal of Experimental Psychology. Human Perception and Performance, 3, 599-606. doi:10.1037/0096-1523.3.4.599

Finke, R. A., \& Shepard, R. N. (1986). Visual functions of mental imagery. In K. R. Boff, L. Kaufman, \& J. P. Thomas (Eds.), Handbook of perception and human performance (Cognitive processes and performance, Vol. 2, pp. 1-55). New York: Wiley.

Fish, W. (2010). Philosophy of perception: A contemporary introduction (1st ed.). Hoboken, NJ: Taylor \& Francis.

Garrett, J. B., \& Wallace, B. (1975). A novel test of hypnotic anesthesia. International Journal of Clinical and Experimental Hypnosis, 23, 139-147. doi:10.1080/00207147508415938

Goldstein, E. B. (2006). Sensation and perception (7th ed.). Belmont, CA: Wadsworth

Goodale, M. A., \& Milner, A. D. (1992). Separate visual pathways for perception and action. Trends in Neurosciences, 15, 20-25. doi:10.1016/0166-2236(92)90344-8

Gregerson, M. B., Roberts, I. M., \& Amiri, M. M. (1996). Absorption and imagery locate immune responses in the body. Biofeedback and Self-Regulation, 21, 149-165.

Harrington, A. (1999). The placebo effect: An interdisciplinary exploration. Cambridge, MA: Harvard University Press.

Harris, C. S. (1965). Perceptual adaptation to inverted, reversed, and displaced vision. Psychological Review, 72, 419-444. doi: $10.1037 / \mathrm{h} 0022616$

Head, H., \& Holmes, H. G. (1911-1912). Sensory disturbances from cerebral lesions. Brain, 34, 102-254.

Hearst, E., \& Knott, J. (2009). Blindfold chess: History, psychology, techniques, champions, world records, and important games. Jefferson NC: McFarland.

Held, R. (1965). Plasticity in sensory-motor systems. Scientific American, 213, 84-94.

Held, R., \& Hein, A. (1963). Movement-produced stimulation in the development of visually guided behavior. Journal of Comparative and Physiological Psychology, 56, 872-876. doi:10.1037/ h0040546

Helmholtz, H. von. (2005). Treatise on physiological optics, (Vol. III). New York: Dover. (Original work published 1866).

Hilgard, E. R., \& Marquis, D. G. (1940). Conditioning and learning. New York: Appleton-Century.

House, J., Landis, K., \& Umberson, D. (1988). Social relationships and health. Science, 241, 540-545. doi:10.1126/science.3399889

Hull, C. L. (1934). Learning II: The factor of the conditioned reflex. In $A$ handbook of general experimental psychology (Vol. xii, pp. 382-455). Worcester, MA: Clark University Press
Irwin, M. R. (2008). Human psychoneuroimmunology: 20years of discovery. Brain, Behavior, and Immunity, 22, 129-139. doi:10.1016/j.bbi.2007.07.013

Janeway, C., \& Travers, P. (1999). Immunobiology: The immune system in health and disease (4th ed.). London: Current Biology.

Kabat-Zinn, J. (2005). Full catastrophe living: Using the wisdom of your body and mind to face stress, pain, and illness. New York: Delta.

Kabat-Zinn, J., Wheeler, E., Light, T., Skillings, A., Scharf, M. J., Cropley, T. G., et al. (1998). Influence of a mindfulness meditation-based stress reduction intervention on rates of skin clearing in patients with moderate to severe psoriasis undergoing phototherapy (UVB) and photochemotherapy (PUVA). Psychosomatic Medicine, 60, 625-632.

Keeley, B. L. (2002). Making sense of the senses: Individuating modalities in humans and other animals. Journal of Philosophy, 99, 5-28.

Keller, M., Baum, M. J., Brock, O., Brennan, P. A., \& Bakker, J. (2009). The main and the accessory olfactory systems interact in the control of mate recognition and sexual behavior. Behavioural Brain Research, 200, 268-276. doi:10.1016/j.bbr.2009.01.020

Kelley, K. W., Bluthé, R.-M., Dantzer, R., Zhou, J.-H., Shen, W.-H., Johnson, R. W., et al. (2003). Cytokine-induced sickness behavior. Brain, Behavior, and Immunity, 17(Suppl. 1), S112S118.

Kirsch, J. (1985). Response expectancy as a determinant of experience and behavior. American Psychologist, 40, 1189-1202.

Klatzky, R. L., \& Lederman, S. J. (2003). Touch. In I. B. Weiner, A. F. Healy, D. K. Freedheim, R. W. Proctor, \& J. A. Schinka (Eds.), Handbook of psychology: Experimental psychology (pp. 147178). New York: Wiley.

Koffka, K. (1999). Principles of Gestalt psychology. London: Routledge (Original work published 1935).

Kravitz, J. H., \& Wallach, H. (1966). Adaptation to displaced vision contingent upon vibrating stimulation. Psychonomic Science, 6 , 465-466.

Kumar, S., Tandon, O. P., \& Mathur, R. (2002). Pain measurement: A formidable task. Indian Journal of Physiology and Pharmacology, 46, 396-406.

Kuper, A. (2005). The social science encyclopedia (3 (rdth ed.). London: Routledge.

Kwekkeboom, K. L., Hau, H., Wanta, B., \& Bumpus, M. (2008). Patients' perceptions of the effectiveness of guided imagery and progressive muscle relaxation interventions used for cancer pain. Complementary Therapies in Clinical Practice, 14, 185-194. doi:10.1016/j.ctcp.2008.04.002

La Roche, M. J., Batista, C., \& D'Angelo, E. (2011). A content analyses of guided imagery scripts: A strategy for the development of cultural adaptations. Journal of Clinical Psychology, 67, 45-57. doi:10.1002/jclp.20742

Laming, D. (1988). Précis of sensory analysis. The Behavioral and Brain Sciences, 11, 275-239. doi:10.1017/S0140525X00049967

Lane, R. P., Roach, J. C., Lee, I. Y., Boysen, C., Smit, A., Trask, B. J., et al. (2002). Genomic analysis of the olfactory receptor region of the mouse and human t-cell receptor $\alpha / \delta$ loci. Genome Research, 12, 81-87. doi:10.1101/gr.197901

Linkins, R. W., \& Comstock, G. W. (1990). Depressed mood and development of cancer. American Journal of Epidemiology, 132, 962-972.

Lowes, M. A. (2004). Current concepts in the immunopathogenesis of psoriasis. Dermatological Clinics, 22, 349-369.

Macpherson, F. (2010). Taxonomising the senses. Philosophical Studies, 153, 123-142. doi:10.1007/s11098-010-9643-8

Macpherson, F. (2011). The senses: Classic and contemporary philosophical perspectives. New York: Oxford University Press. 
Maravita, A., \& Iriki, A. (2004). Tools for the body (schema). Trends in Cognitive Sciences, 8, 79-86. doi:10.1016/j.tics.2003.12.008

Marks, D. F. (1995). New directions for mental imagery research. Journal of Mental Imagery, 19, 153-167.

Menzies, V., \& Kim, S. (2008). Relaxation and guided imagery in Hispanic persons diagnosed with fibromyalgia: A pilot study. Family \& Community Health, 31, 204-212. doi:10.1097/01. FCH.0000324477.48083.08

Menzies, V., Taylor, A. G., \& Bourguignon, C. (2006). Effects of guided imagery on outcomes of pain, functional status, and self-efficacy in persons diagnosed with fibromyalgia. Journal of Alternative and Complementary Medicine, 12, 23-30. doi:10.1089/acm.2006.12.23

Merzenich, M. M., Kaas, J. H., Wall, J., Nelson, R. J., Sur, M., \& Felleman, D. (1983). Topographic reorganization of somatosensory cortical areas $3 \mathrm{~b}$ and 1 in adult monkeys following restricted deafferentation. Neuroscience, 8, 33-55.

Michelon, P., \& Koenig, O. (2002). On the relationship between visual imagery and visual perception: Evidence from priming studies. European Journal of Cognitive Psychology, 14(2), 161-184. doi:10.1080/09541440143000014

Miller, G., \& Cohen, S. (2001). Psychological interventions and the immune system: A meta-analytic review and critique. Health Psychology, 20, 47-63.

Mishkin, M., Ungerleider, L. G., \& Macko, K. A. (1983). Object vision and spatial vision: Two cortical pathways. Trends in Neurosciences, 6, 414-417. doi:10.1016/0166-2236(83)90190-X

Moyé, L. A., Richardson, M. A., Post-White, J., \& Justice, B. (1995). Research methodology in psychoneuroimmunology: Rationale and design of the IMAGES-P clinical trial. Alternative Therapies in Health and Medicine, 1, 34-39.

Müller, J. (2010). Handbuch der Physiologie des Menschen: Für Vorlesungen (Vol. 2). Charleston, NC: Nabu Press. (Original work published 1835)

Nunes, D. F. T., Rodriguez, A. L., da Silva Hoffmann, F., Luz, C., Filho, A. P. F. B., Muller, M. C., et al. (2007). Relaxation and guided imagery program in patients with breast cancer undergoing radiotherapy is not associated with neuroimmunomodulatory effects. Journal of Psychosomatic Research, 63, 647-655. doi:10.1016/j.jpsychores.2007.07.004

Pascual-Leone, A., \& Hamilton, R. (2001). The metamodal organization of the brain. In C. Casanova \& M. Ptito (Eds.), Vision: From neurons to cognition (Vol. 134, pp. 1-19). Amsterdam: Elsevier Science.

Pert, C. B., Dreher, H. E., \& Ruff, M. R. (1998). The psychosomatic network: Foundations of mind-body medicine. Alternative Therapies in Health and Medicine, 4, 30-41.

Porterfield, A. (2005). Healing in the history of Christianity (1st ed.). New York: Oxford University Press.

Post-White, J. (2002). Clinical indication for use of imagery in oncology practice. In D. M. Edwards (Ed.), Voice massage: Scripts for guided imagery (p. 3). Pittsburgh, PA: Oncology Nursing Society.

Pylyshyn, Z. (1999). Is vision continuous with cognition? The case of impenetrability of visual perception. The Behavioral and Brain Sciences, 22, 341-423. doi:10.1017/S0140525X99002022

Radeau, M., \& Bertelson, P. (1976). The effect of a textured visual field on modality dominance in a ventriloquism situation. Perception \& Psychophysics, 20, 227-235. doi:10.3758/ BF03199448

Ramachandran, V. S., Altschuler, E. L., Stone, L., Al-Aboudi, M., Schwartz, E., \& Siva, N. (1999). Can mirrors alleviate visual hemineglect? Medical Hypotheses, 52, 303-305. doi:10.1054/ mehy.1997.0651

Rasmussen, A. F., Jr Marsh, J. T., \& Brill, N. Q. (1957). Increased susceptibility to herpes simplex in mice subjected to avoidance- learning stress or restraint. In Proceedings of the society for experimental biology and medicine (Vol. 96, pp. 183-189). New York: Society for Experimental Biology and Medicine

Redding, G. M. (1979). Attention as an explanatory concept in perceptual adaptation. The Behavioral and Brain Sciences, 2, 77-78.

Redding, G. M., \& Wallace, B. (1990). Effects on prism adaptation of duration and timing of visual feedback during pointing. Journal of Motor Behavior, 22, 209-224.

Redding, G. M., \& Wallace, B. (1997). Adaptive spatial alignment (Illusth ed.). Hove, U.K.: Psychology Press.

Ren, K., \& Dubner, R. (2010). Interactions between the immune and nervous systems in pain. Nature Medicine, 16, 1267-1276. doi: $10.1038 / \mathrm{nm} .2234$

Richardson, A. (1994). Individual differences in imaging: Their measurement, origins and consequences. Amityville, NY: Baywood.

Rider, M. S., Achterberg, J., Lawlis, G. F., Goven, A., Toledo, R., \& Butler, J. R. (1990). Effect of immune system imagery on secretory IgA. Biofeedback and Self-Regulation, 15, 317-333.

Rock, I. (1985). The logic of perception. Cambridge, MA: MIT Press.

Roffe, L., Schmidt, K., \& Ernst, E. (2005). A systematic review of guided imagery as an adjuvant cancer therapy. Psycho-Oncology, 14, 607-617. doi:10.1002/pon.889

Rossetti, Y., Jacquin-Courtois, S., Rode, G., Ota, H., Michel, C., \& Boisson, D. (2004). Does action make the link between number and space representation? Visuo-manual adaptation improves number bisection in unilateral neglect. Psychological Science, 15, 426-430. doi:10.1111/j.0956-7976.2004.00696.x

Sacks, O. (1985). The man who mistook his wife for a hat and other clinical tales. New York: Summit.

Shapiro, A. K. (1959). The placebo effect in the history of medical treatment: Implications for psychiatry. The American Journal of Psychiatry, 116, 298-304. doi:10.1176/appi.ajp.116.4.298

Shapiro, S. L., Carlson, L. E., Astin, J. A., \& Freedman, B. (2006). Mechanisms of mindfulness. Journal of Clinical Psychology, 62, 373-386. doi:10.1002/jclp.20237

Shapiro, A. K., \& Shapiro, E. (1997). The placebo: Is it much ado about nothing? In A. Harrington (Ed.), The placebo effect: An interdisciplinary exploration (pp. 12-36). Cambridge, MA: Harvard University Press.

Shepard, R. N., \& Judd, S. A. (1976). Perceptual illusion of rotation of three-dimensional objects. Science, 191, 952-954. doi:10.1126/ science. 1251207

Simonton, C. O., Simonton-Matthews, S. M., \& Creighton, J. L. (1992). Getting well again: The bestselling classic about the Simontons' revolutionary lifesaving self-awareness techniques. New York: Bantam.

Spanos, N. P., Stenstrom, R. J., \& Johnston, J. C. (1988). Hypnosis, placebo, and suggestion in the treatment of warts. Psychosomatic Medicine, 50, 245-260.

Spanos, N. P., Williams, V., \& Gwynn, M. I. (1990). Effects of hypnotic, placebo, and salicylic acid treatments on wart regression. Psychosomatic Medicine, 52, 109-114.

Spector, N. H. (2011). A tribute to Elena Korneva: Reversal of aging and cancer by Pavlovian conditioning: NeuroimmunomodulationSome history. Neuroscience and Behavioral Physiology, 41, 102116. doi:10.1007/s11055-010-9386-1

Stein, B. E., \& Meredith, M. A. (1993). The merging of the senses. Cambridge, MA: MIT Press.

Stevenson, R. J. (2010). An initial evaluation of the functions of human olfaction. Chemical Senses, 35, 3-20. doi:10.1093/ chemse/bjp083

Stoffregen, T. A., Draper, M. H., Kennedy, R. S., \& Compton, D. (2002). Vestibular adaptation and aftereffects. In K. M. Stanney (Ed.), Handbook of virtual environments: Design, implementation, and applications (pp. 773-790). Mahwah, NJ: Erlbaum. 
Tauber, A. (2010). The biological notion of self and non-self. In E. N. Zalta (Ed.), The Stanford encyclopedia of philosophy. Stanford, CA: Stanford University, Metaphysics Research Lab. Retrieved from http://plato.stanford.edu/archives/sum2010/ entries/biology-self/

Utay, J., \& Miller, M. (2006). Guided imagery as an effective therapeutic technique: A brief review of its history and efficacy research. Journal of Instructional Psychology, 33, 40-43.

Vedhara, K., \& Irwin, M. R. (Eds.). (2005). Human psychoneuroimmunology (1st ed.). New York: Oxford University Press.

Velmans, M. (1991). Is human information processing conscious? The Behavioral and Brain Sciences, 14, 651-669. doi:10.1017/ S0140525X00071776

Walk, R. D., \& Pick, H. L., Jr. (Eds.). (1981). Intersensory perception and sensory integration. New York: Basic Books.

Walker, L. G., Walker, M. B., Ogston, K., Heys, S. D., Ah-See, A. K., Miller, I. D., et al. (1999). Psychological, clinical and pathological effects of relaxation training and guided imagery during primary chemotherapy. British Journal of Cancer, 80, 262-268. doi:10.1038/sj.bjc.6690349

Wallace, B. (1980). Factors affecting proprioceptive adaptation to prismatic displacement. Perception \& Psychophysics, 28, 550554. doi:10.3758/BF03198824

Wallace, B., \& Fisher, L. E. (1984). Prism adaptation with hypnotically induced limb anesthesia: The critical roles of head position and prism type. Perception \& Psychophysics, 36, 303306. doi:10.3758/BF03206372

Wallach, H. (1968). Adaptation based on cue discrepancy. In R. Held, E. Taub, \& S. J. Freeman (Eds.), The neuropsychology of spatially oriented behavior (pp. 235-259). Homewood, IL: Dorsey Press.

Wallach, H., \& Frey, K. J. (1972). On counteradaptation. Perception \& Psychophysics, 11, 161-165. doi:10.3758/BF03210365
Weil, A. (1995). Spontaneous healing: How to discover and enhance your body's natural ability to maintain and heal itself. New York: Knopf.

Weisfeld, G. E., Czilli, T., Phillips, K. A., Gall, J. A., \& Lichtman, C. M. (2003). Possible olfaction-based mechanisms in human kin recognition and inbreeding avoidance. Journal of Experimental Child Psychology, 85, 279-295.

Weiskrantz, L. (1986). Blindsight: A case study and implications (1st ed.). New York: Oxford University Press.

Welch, R. B. (1978). Perceptual modification: Adapting to altered sensory environments. New York: Academic Press.

Welch, R. B., Warren, D. H., et al. (1986). Intersensory interactions. In K. R. Boff \& L. Kaufman (Eds.), Handbook of perception and human performance: Sensory processes and perception, cognitive processes and performance (pp. 25.1-25.36). New York: Wiley.

Wells, J. (2010). Transpersonal awareness, mindfulness meditation, and guided imagery: A qualitative study using concise narrative vignettes (p. 70). Dissertation Abstracts International: Section B. Sciences and Engineering.

Wolpe, J. (1973). The practice of behavioral therapy (2nd ed.). New York: Pergamon Press.

Wundt, W. M. (2009). An introduction to psychology: 1912. Ithaca, NY: Cornell University Library (Original work published 1912).

Yamamoto, S., \& Kitazawa, S. (2001). Sensation at the tips of invisible tools. Nature Neuroscience, 4, 979-980. doi:10.1038/ nn721

Yost, S. (2003). Audition. In I. B. Weiner, A. F. Healy, D. K. Freedheim, R. W. Proctor, \& J. A. Schinka (Eds.), Handbook of psychology: Experimental psychology (pp. 121-146). New York: Wiley.

Zajicek, G. (1995). The placebo effect is the healing force of nature. Cancer Journal, 8, 4-5. 